\title{
A silver bullet in a golden age of functional genomics: the impact of Agrobacterium-mediated transformation of fungi
}

\author{
Alexander Idnurm ${ }^{1 *} \mathbb{D}$, Andy M. Bailey ${ }^{2}$, Timothy C. Cairns ${ }^{3}$, Candace E. Elliott ${ }^{1}$, Gary D. Foster ${ }^{2}$, Giuseppe laniri ${ }^{4}$ \\ and Junhyun Jeon ${ }^{5}$
}

\begin{abstract}
The implementation of Agrobacterium tumefaciens as a transformation tool revolutionized approaches to discover and understand gene functions in a large number of fungal species. A. tumefaciens mediated transformation (AtMT) is one of the most transformative technologies for research on fungi developed in the last 20 years, a development arguably only surpassed by the impact of genomics. AtMT has been widely applied in forward genetics, whereby generation of strain libraries using random T-DNA insertional mutagenesis, combined with phenotypic screening, has enabled the genetic basis of many processes to be elucidated. Alternatively, AtMT has been fundamental for reverse genetics, where mutant isolates are generated with targeted gene deletions or disruptions, enabling gene functional roles to be determined. When combined with concomitant advances in genomics, both forward and reverse approaches using AtMT have enabled complex fungal phenotypes to be dissected at the molecular and genetic level. Additionally, in several cases AtMT has paved the way for the development of new species to act as models for specific areas of fungal biology, particularly in plant pathogenic ascomycetes and in a number of basidiomycete species. Despite its impact, the implementation of AtMT has been uneven in the fungi. This review provides insight into the dynamics of expansion of new research tools into a large research community and across multiple organisms. As such, AtMT in the fungi, beyond the demonstrated and continuing power for gene discovery and as a facile transformation tool, provides a model to understand how other technologies that are just being pioneered, e.g. CRISPR/Cas, may play roles in fungi and other eukaryotic species.
\end{abstract}

Keywords: Functional genomics, Mycota, Pathogenicity genes, Rhizobium radiobacter, Transfer DNA

\section{Background}

In 1998, Dunn-Coleman and Wang published a commentary on a newly described system for the transformation of foreign DNA into filamentous fungi using Agrobacterium tumefaciens: the catchy term in their article's title was that this method was potentially a "silver bullet" [1]. We think of a "silver bullet" as a missile to combat werewolves or other fantasy monsters, yet here there is an

\footnotetext{
*Correspondence: alexander.idnurm@unimelb.edu.au

1 School of BioSciences, University of Melbourne, Melbourne, VIC 3010, Australia

Full list of author information is available at the end of the article
}

additional metaphor; DNA is shot into a fungal genome to cause damage to a key gene, and thereby that can provide information on the strengths and weaknesses of the fungus. This remarkable use of a plant pathogenic bacterium, A. tumefaciens, to transform fungi had first been demonstrated in the model yeast Saccharomyces cerevisiae just a few years earlier [2,3], and then extended in 1998 to seven species of filamentous fungi in both the Ascomycota and Basidiomycota lineages [4]. Within a decade from its first reported use in S. cerevisiae, by 2005 over 50 fungal species had been transformed with $A$. tumefaciens [5]. In the decade since then, the use of $A$. tumefaciens mediated transformation (AtMT) continued 
to expand to become a standard experimental technique within the tool-box for gene manipulation in many fungal species. For some species it became the easiest or even the only method by which to introduce foreign DNA. In other species, it emerged as a powerful technique for forward genetics, for use in the creation of large collections of strains carrying random T-DNA insertions and their analysis, for reverse genetics to create specific targeted gene replacements, or for manipulation of gene expression for biotechnological benefits.

In this review we describe the rise and influence of AtMT on the understanding of fundamental aspects of fungi. We describe species or groups of fungi in which AtMT has had greatest impact, some of the limitations that have subsequently emerged in applications, and areas of research or fungal species in which this transformation technology did not have as great an impact. Understanding how this technology was implemented can guide or anticipate the benefits of future technologies for advancing research on fungi.

It is not possible to include specific details from all the publications reporting the use of $A t \mathrm{MT}$ on fungi, even if covering those since the review by Michielse et al. [5]. A PubMed search of "Agrobacterium AND fungus" returns more than 900 papers, and as an example in the Cryptococcus neoformans species complex alone AtMT has been used in more than 30 studies. Other comprehensive and insightful reviews address specific aspects of this technique, e.g. different vectors that are available [6], or the proteins encoded by $A$. tumefaciens that are required to transform organisms $[7,8]$, which this review aims to complement. Finally, "impact" is relative in that what may appear important to one set of researchers may not to another set, while individual people may have personal favorite experiments or discoveries made using the technique.

\section{Agrobacterium tumefaciens and how it transforms species}

Agrobacterium tumefaciens is a plant pathogen in the class $\alpha$-Proteobacterium that is best known as one of nature's natural agents in creating genetically modified organisms. In this process, the bacterium inserts a piece of a plasmid into the nucleus of the plant host cell, and in the wild that bacterial DNA encodes proteins that modify the plant growth in favor of the bacterium. In most circumstances, this results in the formation of a nonproliferative gall or tumor-like growth on a plant, with alterations in the recipient genome that are not normally carried on into subsequent plant generations. However, analysis of the genome of sweet potato indicates that in rare cases these transformation events can be integrated more permanently into the genome [9]. The Agrobacterium genus is within the family Rhizobiaceae and as such it is closely related to the genus Rhizobium, members of which also form intimate associations with plants to fix atmospheric nitrogen. A. tumefaciens was renamed Rhizobium radiobacter [10], although the community using this species as a transformation technology for fungi continues to use the name $A$. tumefaciens.

Before the development of genome sequencing projects, the only known example of horizontal gene transfer from bacteria to eukaryotes was the trans-conjugation mediated by $A$. tumefaciens [11]. Agrobacterium naturally exists in an environment where it encounters numerous hosts, including fungi that are likely to be present at the plant wounds, which induce T-DNA transfer. Knight et al. [12] demonstrated that it is entirely feasible that such transformation events happen in a natural environment. They co-cultivated the plant pathogenic fungus Verticillium albo-atrum on plant material alongside an Agrobacterium strain containing a plasmid that could potentially transform fungi, and observed transformation of the fungus under these in planta conditions [12]. Of course, in the wild such an event is unlikely to deliver any beneficial DNA sequence into the fungus, so may well not confer any selectable advantage, but it is interesting to speculate on the frequency of such events over an evolutionary timescale: indeed, in addition to plants [9], genome sequencing projects have identified Agrobacterium-like DNA in the genomes of some fungi such as Aspergillus oryzae [13].

Plant molecular biologists altered wild strains of $A$. tumefaciens to their own advantage. The bacterial strains and genetic material were modified to prevent gall formation, and to establish systems in which DNA for transformation into a plant can be placed between two direct repeats of $25 \mathrm{bp}$ (the left and right borders of the transfer or T-DNA) (Fig. 1). From the perspective of bacterial genetics, rather than transformation it is more accurate to describe the movement of the T-DNA from the bacterium into the eukaryotic host as a trans-conjugation method of gene transfer, in this case a conjugation mechanism that is capable of occurring across different species. The promiscuous nature of $A$. tumefaciens, to target a wide diversity of hosts, enabled it to be applied to numerous other eukaryotic species, with members of the fungi being the best examples beyond the model plant Arabidopsis thaliana [11].

One of the initial downsides of transformation of fungi with Agrobacterium was the perceived inflexibility with the vector systems. Some of the Agrobacterium vectors were rather unwieldy, with limited restriction sites for conventional cloning and, having been developed for 


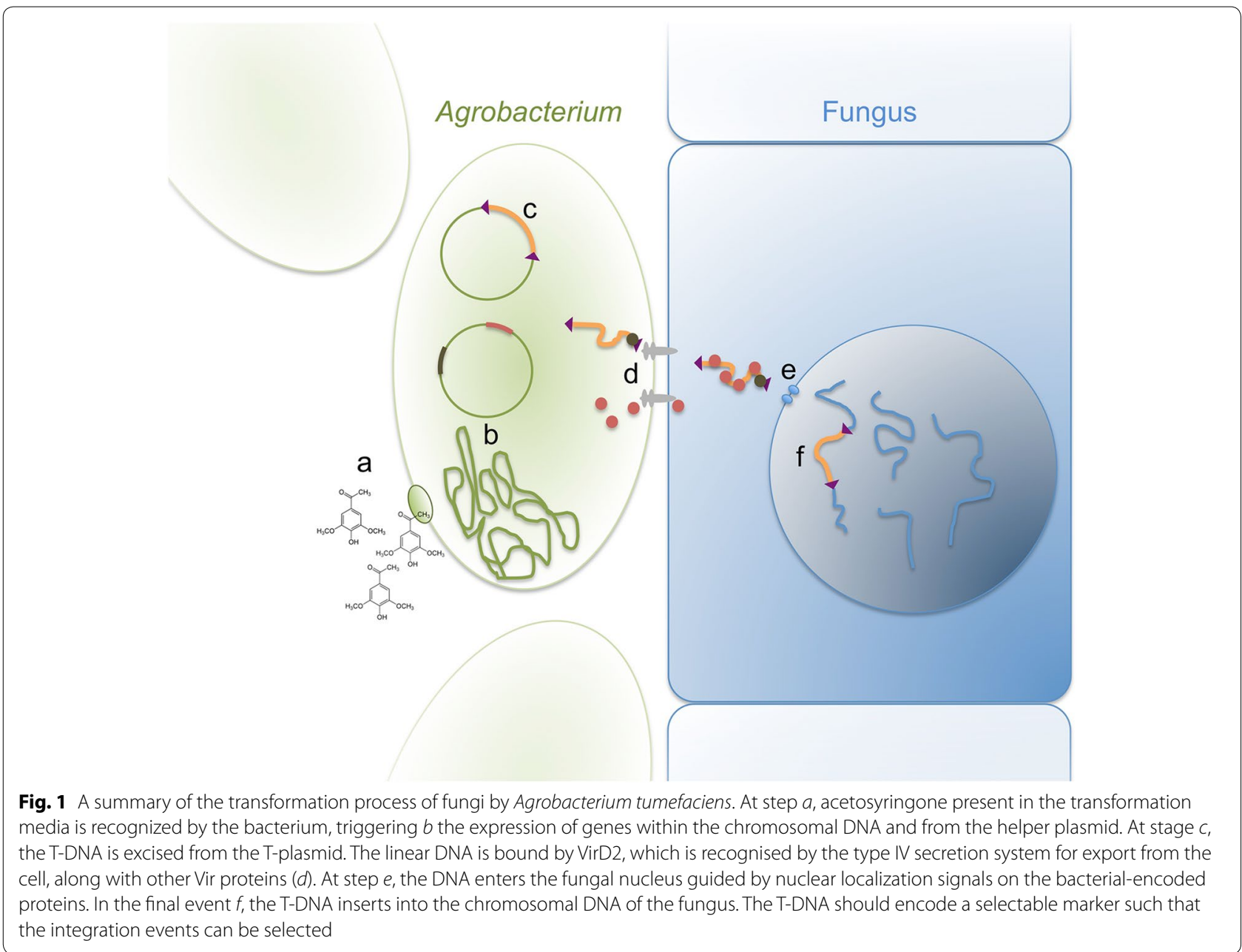

plants, were prefabricated with selection cassettes and regulatory elements specifically for plant transformation. Fortunately some of the suites of vectors made for plants (e.g. pGreen, pCambia, etc.) also included small vectors that had empty T-DNA regions that were amenable to easy manipulation. These have been updated to allow vector construction by means such as yeast recombination in S. cerevisiae [14-16], the Gateway system [17] or Golden Gate assembly [18], making vector construction and deployment simple and amenable to high throughput approaches.

Another limit of the early vectors was the length of DNA that could be inserted, which was a significant technical restriction for complementation of large genes. One solution to this problem was the development of the BIBAC system, which enabled the modification of any bacterial artificial chromosome (BAC) containing a large piece of fungal DNA to contain left and right border sequences, thus enabling direct fungal transformation. Large fragments (up to $75 \mathrm{~kb}$ ) of DNA were successfully transferred into the Fusarium oxysporum f. sp. lycopersici genome using this method [19]. In a similar manner, a system to convert BACs into vectors suitable for $A t \mathrm{MT}$ in the Ustilago maydis has also been developed [20].

\section{Advantages of AtMT over other transformation techniques}

Transformation tools existed for fungi prior to the development of $A t \mathrm{MT}$, for example using the protoplast/polyethylene glycol or cation/polyethylene glycol approaches $[21,22]$. However, AtMT provided improvements over many of these methods, explaining why it became a transformation tool of choice in many fungal species.

Firstly, AtMT eliminates the need to remove the fungal cell wall to make protoplasts. While protoplasting is an established method in some species, in others it is difficult and variable in success. Fungi have a suite of cell wall types that differ between species and that change at different stages during growth and development. These differences likely explain why the ease and success of 
protoplasting vary between species; this is not helped by the difficulties in obtaining suitable cell wall degrading enzymes. In contrast, although Agrobacterium does show cell type preferences, as discussed later in the section on the mushroom-forming Agaricomycotina, Agrobacterium can transform species across a wide spectrum of evolution, including mammalian cells [23] and oomycetes [24], and many different tissue or cell types in fungi.

A second significant advantage to AtMT over other approaches is that the T-DNA can integrate randomly into the genome. Consequently, much of the impact of AtMT comes from the perspective of random mutagenesis as a resource for forward genetic screens. At the time of development of $A t \mathrm{MT}$, the process of restriction enzyme mediated integration (REMI) was the insertional mutagenesis method of choice. This method includes restriction enzymes in the stage when DNA is transformed into protoplasted cells. A number of problems arose with this method such as mutations not linked to the inserted DNA, which were proposed to be caused by the restriction enzymes causing damage to the DNA. Other insertional mutagenesis tools include transposon insertions, although these usually require the design of specific constructs for each species. AtMT largely superseded REMI as the insertional mutagenesis tool in fungi [5]. Usually the T-DNA inserts as a single copy into the genome, so any change in phenotype is likely caused by the insertion. After screening libraries of T-DNA insertion transformants for phenotypes, either side of the T-DNA insert are then obtained by difference methods, which are most often PCR-based, in order to identify the affected gene. Typically, the function of the genes identified using T-DNA mutagenesis is confirmed through (a) linkage analysis of the progeny obtained from crosses between a strain of opposite mating type and the T-DNA mutant, if the mutation does not affect the sexual cycle; (b) generation of a targeted replacement allele by means of transformation techniques suitable for the studied organism, or (c) complementation with a wild type copy of the gene.

Thirdly, AtMT is amenable for use in reverse genetic approaches for targeted gene deletion or disruption. This differs from random insertional mutagenesis, as transformation vectors are supplemented with DNA sequences that mediate homologous recombination of the exogenous cassette with specific loci of the recipient genome. Thus, AtMT can be used for targeted replacement at desired genomic regions, most obviously a putative open reading frame. AtMT was often developed in conjuncture with the isolation of mutants in the nonhomologous end joining DNA repair process [25]. Mutation of this pathway helps increase the proportion of transformants that have gene replacements. Over the past decade, there has been a rapid increase in publicly available genome sequences of fungi [26], which has enabled facile identification of individual genes or gene families that can be analyzed by targeted gene deletion. This has occurred in parallel with development of numerous molecular tools, including inducible promoter systems [27], recyclable markers [25] and most recently CRISPRCas genome editing [28]. These techniques now promise functional genomic analyses at a high throughput level, and systems-level insight into industrial tractability, processes essential for disease, and putative drug targets of many fungi [29]. Consequently, targeted manipulation of fungal genomes using AtMT is a critical technique that will facilitate the implementation of more recent breakthroughs.

Finally, having a method for easy transformation "leveled the playing field" for discovering gene function in what had up until then been dominated by the model species for molecular biology experiments. This particularly became the case for non-conventional species as soon as their genome sequence became available. Examples are given later in this review.

\section{Trends in the research of fungi using AtMT}

In their 2005 review, Michielse et al. [5] described specific features about AtMT, and then some research trends many that continued over the following decade. A large focus has been on the efficiency of transformation as influenced by co-culture conditions, e.g. bacterial and fungal cell concentrations, temperature, length of co-incubation, and concentration of acetosyringone, which is a plant metabolite released from wounded roots that enhances A. tumefaciens transformation (Fig. 1). The direction of this focus on transformation efficiency relates to the prior challenges in obtaining large numbers of transformants from protoplasts or other methods, and hence the efforts to optimize conditions to maximize the number of transformants obtained per experiment. However, this is not crucial because AtMT is technically easy, and if more transformants are needed they can be obtained just by increasing the number of transformation experiments to be performed. Conversely, it is ideal to generate a library of single T-DNA insertion mutants quickly and unequivocally link the phenotype of interest with the genetic mutation, but little work has addressed if the numbers of transformants obtained correlate with the number of integration events per transformant. There is a tendency for more publications reporting the first use of $A t \mathrm{MT}$ in a species, and fewer on the full implementation of the technique for making mutations in genes, or other purposes. Given that the following examples represent only a small proportion of all species successfully transformed using Agrobacterium, there remains a large 
untapped resource waiting for gene discovery in a wide diversity of fungi.

\section{Fungal species and biological questions in which AtMT made greatest contributions}

Application of AtMT depends on the question being asked, and this versatile tool has suited answering such questions in different fungi. Approaches include individual gene deletion or disruption experiments, analyses of gene classes resulting in several dozen mutant strains, to the generation of large libraries consisting of thousands of strains. Nevertheless, it is notable that some species, or indeed fungal lineages, have more widely adapted $A t \mathrm{MT}$ as a common research tool. The following sections are divided based on the evolution of the fungi (Fig. 2): examples from Ascomycetes with the focus on the plant pathogens, Basidiomycetes, and a brief section on the earlier, paraphyletic fungal lineages.

\section{Phylum Ascomycota and the role of AtMT} on understanding gene functions in plant pathogenicity The impact of AtMT in the ascomycetes has been of greatest relevance to the plant pathogens, with little impact on model species like $S$. cerevisiae, Neurospora crassa or Aspergillus nidulans wherein a long history of research and efficient methods for transformation, classical genetics, and gene identification were already in place. There are thousands of ascomycete species that infect plants. One way to measure the impact of AtMT is to examine its role in understanding gene functions in particularly problematic species. In a proposed "top ten" list of plant pathogens (Table 1, [30]), many species benefited from this technique. For those species that did not benefit, this was either because efficient methods for transformation and gene discovery were already available for them (e.g. the basidiomycete $U$. maydis) or because they are obligate pathogens and therefore difficult to co-culture with Agrobacterium (e.g. Puccinia species, Blumeria graminis and Melampsora lini). In the diverse species in which AtMT was adopted, this technology opened the opportunity for high throughput mutant screens or construction of mutant libraries. Thus, AtMT has been applied to a number of plant pathogenic fungi including many of the economically important pathogens. Although T-DNA integration varies depending on the system, AtMT has been consistently an efficient tool for the genetic study of fungal pathogenesis. The following sections describe ascomycete plant pathogenic species or genera in which AtMT has been widely used, and finishes with one human pathogen example.

\section{Pyricularia oryzae}

Pyricularia oryzae (Sordariomycetes) is the causal agent of rice blast, the most serious disease of cultivated rice. The species is also referred to as Magnaporthe oryzae or M. grisea in older literature [31]. Rice blast disease

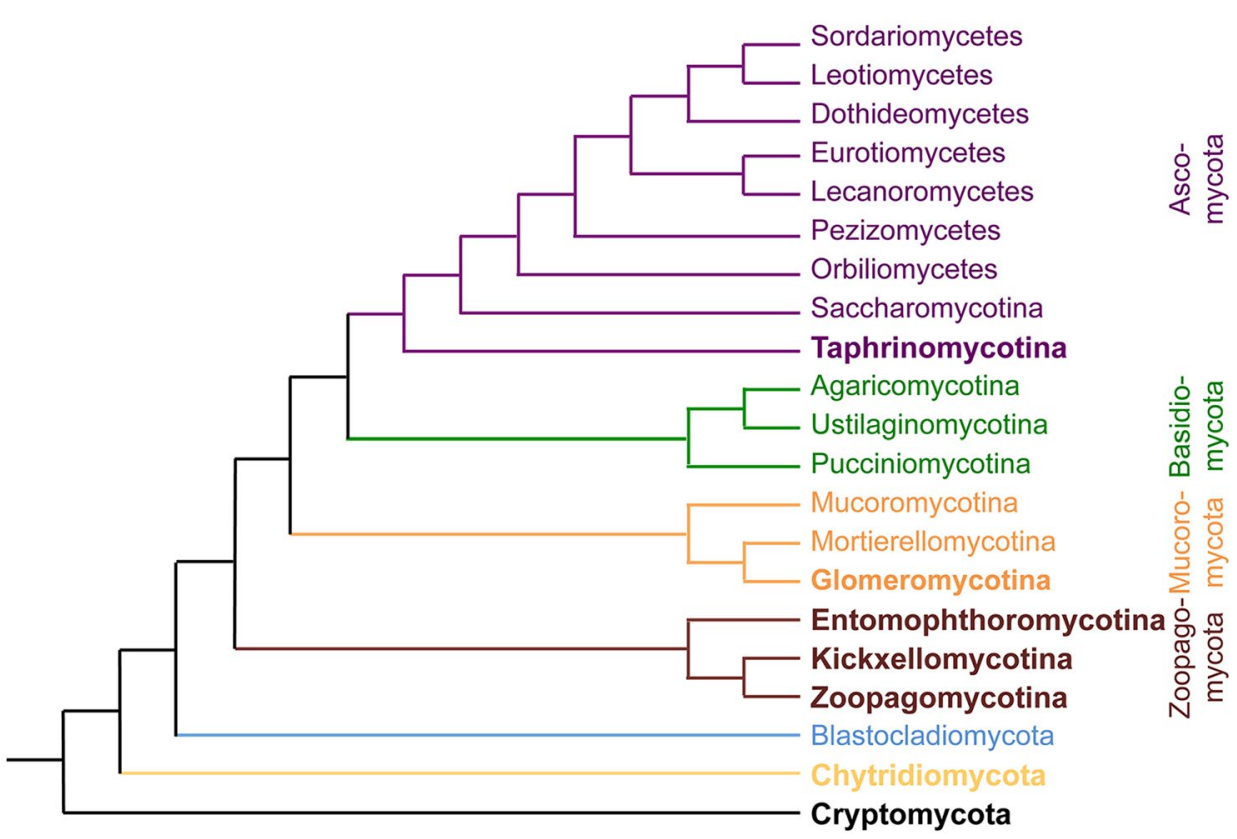

Fig. 2 Phylogeny of major lineages within the fungi. The relationships are based on references [204, 243]; note that some nodes remain poorly defined. For hierarchy: phylum -mycota, subphylum -mycotina, class -mycetes. The Pezizomycotina subphylum is split into seven classes in the phylogeny. Groups in which species have not yet been transformed successfully by Agrobacterium are in bold 
Table 1 A "top ten" list of fungal plant pathogens for research at the molecular biology level [30], and the impact of AtMT on these species

\begin{tabular}{|c|c|c|c|c|c|}
\hline Rank & Name & Growth capabilities & AtMT success & Impact & Key references \\
\hline 1 & Pyricularia oryzae (Magnaporthe oryzae) & In vitro & Yes & Major & {$[15,38-42]$} \\
\hline 2 & Botrytis cinerea & In vitro & Yes & Modest & [244] \\
\hline 3 & Puccinia spp. & Obligate pathogen & No & N/A & N/A \\
\hline 4 & Fusarium graminearum & In vitro & Yes & Minor & {$[65]$} \\
\hline 5 & Fusarium oxysporum & In vitro & Yes & Major & {$[75,76]$} \\
\hline 6 & Blumeria graminis & Obligate pathogen & No & $\mathrm{N} / \mathrm{A}$ & N/A \\
\hline 7 & Zymoseptoria tritici (Mycosphaerella graminicola) & In vitro & Yes & Major & {$[52-54,245]$} \\
\hline 8 & Colletotrichum spp. & In vitro & Yes & Major & {$[84,86]$} \\
\hline 9 & Ustilago maydis & In vitro & Yes & Minor & [198] \\
\hline 10 & Melampsora lini & Obligate pathogen & Yes & Minor & {$[176]$} \\
\hline
\end{tabular}

destroys enough rice to feed 60 million people every year [32]. Considering that rice is a staple food accounting for major caloric and protein intake in many countries (http://www.irri.org/), the disease is one of the major threats to global food security. Due to the experimental tractability of $P$. oryzae and the socioeconomic impact of rice blast, the fungus has served as an important model to understand the biology of fungal plant pathogens [33, 34]. Although genome sequence information had offered great opportunities to discern possible genetic attributes that confer pathogenicity on the fungus [35], low efficiency of gene knockout hampered translating genome sequences into meaningful biological information. To overcome this bottleneck, insertional mutagenesis techniques such as restriction enzyme-mediated integration (REMI) and transposon-arrayed gene knockout (TAGKO) were developed to generate mutants and examine the function of disrupted genes [36,37].

The first demonstration of AtMT for large-scale analysis of gene functions in any plant pathogenic fungus came from a study in which over 20,000 P. oryzae insertional transformants were generated [38]. Southern blot analysis revealed that $>80 \%$ of transformants had a single T-DNA copy within their genome. In parallel, laboratories in the USA [39] and China produced more than 150,000 AtMT mutants, establishing the most extensive insertional mutant libraries in any plant pathogenic fungus.

Analyses of T-DNA insertion patterns in the P. oryzae transformants showed that T-DNA integration favored promoter regions of genes that have an AT-rich base composition [40-42]. In addition, direct or inverted repeats of T-DNA, chromosomal rearrangements and inclusion of additional plasmid vector were also observed. Despite these biases, T-DNA insertions are relatively evenly distributed throughout all of the chromosomes, suggesting the potential of AtMT as a tool for forward genetics. A high throughput phenotype screening system was developed to identify and characterize the transformants that are affected in key developmental steps of the life cycle, including pathogenicity [38]. The screens yielded more than 180,000 data points, which are archived and analyzed by a relational database (http://atmt.riceblast.snu. ac.kr/) (Fig. 3). Such high throughput phenotype screening in combination with identification of genes tagged by T-DNA in individual mutants led to the identification of 203 independent loci implicated in fungal pathogenicity. This represents the largest, unbiased set of putative pathogenicity genes for a single fungal species. The majority of putative pathogenicity genes tagged by T-DNA in the study included novel genes, although the list contained known pathogenicity genes, such as NTH1, which encodes neutral trehalase [43]. The value of the AtMT approach is exemplified by many subsequent discoveries of genes that control aspects of fungal pathogenicity. One example amongst many is the detailed analysis of a novel gene, DES1 (plant defense suppression 1), required for the suppression of the basal defense responses in the host plant [44]. DES1 was identified from a T-DNA insertion site that was $750 \mathrm{bp}$ from the closest predicted gene, and analysis of progeny of sexual crosses confirmed the segregation of antibiotic resistance with this interesting phenotype of aberrant conidial morphogenesis. This is an example of a gene that would not have been prioritized for analysis via a reverse genetics approach as it encodes a serine rich protein with no obvious functional domains or characterized homologues in other ascomycetes.

AtMT can also be used to make gene replacement mutant strains in P. oryzae. For example, binary plasmids have been generated that are compatible with replication in Agrobacterium and S. cerevisiae, thus enabling assembly of transformation vectors using yeast recombinational cloning [15]. Such vectors can be used to create targeted gene knockouts in $P$. oryzae by homologous 


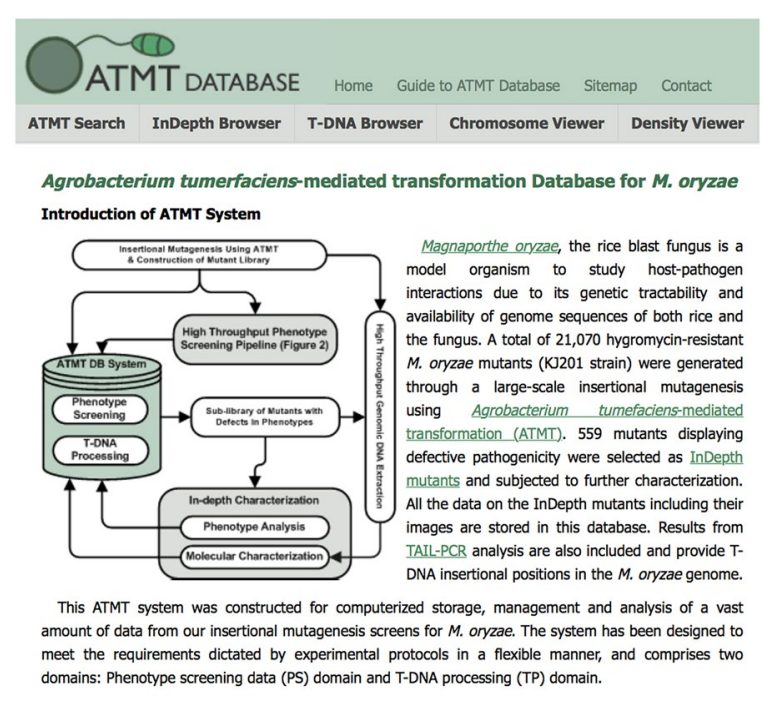

Fig. 3 Databases of T-DNA insertion sites, mutant phenotypes, and strain availability have been developed for some fungal species. A screen shot of the front page of the ATMT Database (http://atmt.snu. ac.kr) that features information on T-DNA mutants of $P$. oryzae, primarily based on information from [38]. Limited funding for maintaining such databases and strain resources after projects end may undermine the potential impact of large-scale mutant screens

integration: for example, a library of 102 deletion strains in genes encoding $\mathrm{Zn}_{2} \mathrm{Cys}_{6}$-type transcription factors was created, with phenotypic analysis defining 61 regulators of development and eight required for infection of rice and barley [15].

Thus, for P. oryzae, AtMT has had two directions of impact for gene function discovery. One was through forward genetics by screening tens of thousands of T-DNA insertional mutants. The second was in creating gene replacement strains, which were then tested for pathogenicity on plants.

\section{Zymoseptoria tritici}

Zymoseptoria tritici (previously named Mycosphaerella graminicola; Dothideomycetes) causes the most important foliar disease of wheat, Septoria blotch, with average yield losses of 5-10\% annually [45]. Throughout Europe, the crop destruction and deployment of antifungals to combat Z. tritici are estimated to run into billions of Euros, with losses in Germany, for example, estimated to cost 500 and 310 million per year, respectively [45]. Worryingly, resistance of $Z$. tritici to every class of antifungal compounds is increasing, yet the number of new compounds developed to combat this pathogen is in decline [46]. Consequently, validation of new pathogen targets for rational fungicide development, concomitant with development of highly resistant wheat varieties, are pressing objectives for food security. AtMT has been essential for improved understanding of the molecular basis of $Z$. tritici infection, which may ultimately lead to durable disease control strategies.

The first transformation of $Z$. tritici utilized a classical protoplast-polyethylene glycol (PEG) approach, whereby the cell walls of in vitro grown conidia were digested and a DNA cassette encoding hygromycin or carbendazim resistance was introduced into recipient genomes [47]. From this study, several limitations to protoplast-based transformation became apparent. Firstly, there were significant variations in successful protoplast generation between $Z$. tritici isolates. Secondly, this experimental challenge was further complicated by the commercial discontinuation of Novozyme 234, which was the enzyme mix used to digest conidial cell walls [47]. While other enzyme preparations exist for fungal protoplasting [48], variations in availability of validated transformation reagents introduced an additional challenge for the widespread adoption of this approach by the $Z$. tritici research community.

Consequently, with few exceptions [47, 49, 50], molecular studies of $Z$. tritici rely on AtMT [51]. As one example, a T-DNA mutagenesis forward genetic screen generated an insertional library of $615 \mathrm{Z}$. tritici transformants [52]. Virulence analysis of this mutant library revealed one isolate, 5-29H, which was avirulent in a detached leaf infection assay. Mapping of the T-DNA insertion locus revealed disruption of a putative mannosyltransferase-encoding gene, and subsequent phenotypic screening and proteomic analyses demonstrated that protein $N$-glycosylation was essential for a switch from yeast-like conidia to infectious hyphal growth, and ultimately successful disease initiation [52]. Using AtMT in a targeted approach, Cousin and co-workers deleted a mitogen-activated protein kinase (MAPK) encoding gene that had high sequence homology to the FUS3 gene of $S$. cerevisiae [53]. This MAPK plays a critical role in mating and growth in this yeast, and deletion in $Z$. tritici resulted in aberrant polarized growth and deficiencies in host penetration during infection. In a similar approach using AtMT, deletion of a gene encoding another MAPK, termed MgSlt2, demonstrated a critical role of this gene in resistance to several fungicides, and hyphal branching following leaf penetration [54]. Taken together, these studies demonstrate that impaired hyphal development, deficient stomatal penetration [53], or an inability to proliferate after disease initiation [54] all result in reduced pathogenicity, and ultimately suggest interference with the normal $Z$. tritici developmental program offers an opportunity to inhibit disease. Thus, AtMT represents a critical tool in the researchers' repertoire for identifying the targets for the rational development of novel 
fungicides. With regards to future $Z$. tritici experiments, and the molecular analyses of phytopathogenic fungi in general, it is clear that $A t \mathrm{MT}$ will continue to be utilized even in face of major paradigm shifts in the field of fungal pathogenicity.

\section{Fusarium species}

Members of the Fusarium genus (Sordariomycetes) include agronomically important plant pathogens some of which are known for producing mycotoxins and also as opportunistic human pathogens [55]. One recent phylogenetic study suggests that the Fusarium genus could be subdivided into 20 species complexes with the terminal Fusarium clade originating in the middle Cretaceous period [56]. The most intensely studied Fusarium species include members of the species complexes Sambucinum (F. graminearum, $F$. pseudograminearum and $F$. culmorum causing blights and rots of wheat and barley), Fujikuroi (F. fujikuroi causing bakane disease of rice and F. verticillioides causing ear rot of maize), and Oxysporum (a species complex of soil-borne filamentous fungi whose members include more than 12 forma speciales causing vascular wilts of many different plant species). The Oxysporum complex has been a focus of interest to evolutionary biologists due to the range of life strategies of its members. Although all members are soil-borne, not all isolates are plant pathogens, a feature associated with the elevated genome plasticity of Fusarium and that allow the acquisition of mobile pathogenesis chromosomes [57]. Moreover, the finding that an isolate pathogenic on tomato can cause disease in immunocompromised mice raised the profile of this species complex as a model for cross-kingdom pathogenesis studies [58]. Given the size, diversity and economic damage caused by members of the genus it is not surprising that AtMT has made an impact on some species of Fusarium more than others, and therefore the main focus of this section will be on a limited number of species such as $F$. graminearum and $F$. oxysporum.

In the first comprehensive report of transformation of a Fusarium species (F. oxysporum f. sp. raphani strain 699), the efficiency ranged from 1 to 40 transformants per $10^{7}$ protoplasts [59]. Although transformation efficiency using protoplasting methods was low, homologous recombination was easily achieved in $F$. oxysporum and $F$. graminearum with $20-50 \%$ homologous integration events $[60,61]$, opening the way for reverse genetic experiments. The development of AtMT for filamentous fungi including $F$. venenatum, the source of the edible mycoprotein Quorn ${ }^{\mathrm{TM}}$, promised to improve transformation efficiency for the genus Fusarium [4]. Two more Fusarium species, $F$. circinatum and $F$. oxysporum, were transformed in 2001, providing new vectors for fungal transformation as well as a plasmid rescue cassette to enable the easy retrieval of DNA sequences flanking the T-DNA insertion in the fungal genome [62, 63]. These publications reported improved transformation efficiencies to 300-500 transformants per $10^{6}$ conidia thus paving the way for further forward genetic approaches in Fusarium [64]. Since 2001, AtMT has been reported in at least nine Fusarium species including F. culmorum, F. graminearum, F. pseudograminearum [65], F. verticillioides [66], F. virguliforme [67], and $F$. avenaceum [68].

Although F. graminearum can be transformed by $A$. tumefaciens, the efficiency of AtMT using non-homologous DNA is extremely low. Malz et al. [65] compared the efficiency of AtMT for the random integration of a hygromycin resistance cassette into three species of Fusarium and found that in a single transformation experiment $F$. pseudograminearum yielded 409 transformants, whereas F. culmorum and F. graminearum yielded only 13 and 9 transformants, respectively. Interestingly, $F$. graminearum can be transformed to high efficiency (up to 2000 transformants per $10^{7}$ conidia) with $A t \mathrm{MT}$ as long as the vector used contains some homologous $F$. graminearum DNA within it, suggesting that homologous recombination may be the dominant type of integration event in $F$. graminearum as it is in S. cerevisiae [69]. Consequently REMI, and not AtMT, is still used for forward genetics approaches in . graminearum [70].

In contrast, $A t \mathrm{MT}$ is clearly the method of choice for large-scale random mutagenesis approaches in $F$. oxysporum. The first random mutagenesis studies published were done using REMI [71, 72] or transposon tagging $[73,74]$ with numbers of mutants generated in the range of 182-1129. AtMT has enabled studies of a much larger scale. In 2009, two large-scale studies were published using AtMT. Screening of a mutant collection of 10,290 transformants of $F$. oxysporum f. sp. lycopersici identified 106 isolates with reduced pathogenicity on tomato and 111 potential pathogenicity genes [75]. Similarly, Li et al. [76] created a bank of 20,000 mutants of $F$. oxysporum f. sp. cubense race 4, and screened them over a 6-year period for reduced pathogenicity on Cavendish banana plantlets. This revealed 27 reduced or loss of pathogenicity isolates, one of which had a T-DNA insertion in the gene FoOCH1 that encodes an $\alpha-1-6$-mannosyltransferase. Interestingly, further characterization of $\mathrm{FoOCH} 1$ via targeted deletion and complementation experiments was achieved by transforming protoplasts, illustrating that in contrast with fungal systems covered in other sections of this review, there is a choice of efficient transformation methods available to researchers working on $F$. oxysporum. 


\section{Colletotrichum species}

The genus Colletotrichum (Sordariomycetes) contains a large number of plant pathogens causing diseases in most crops, including grains and fruit, as well as resulting in post-harvest losses [30, 77, 78]. Many species are hemibiotrophs (i.e. growing first as a biotroph without causing disease symptoms before switching to a necrotrophic mode of damage), although some purely nectrotophic species are also known.

Early insertional mutagenesis approaches in Colletotrichum spp. yielded discoveries into genes required for pathogenicity, indicating that insertional mutagenesis would be an effective approach for gene discovery. Examples of successful gene identification include those encoding a class V chitin synthase in C. graminicola [79] and a serine/threonine protein kinase in C. lindemuthianum [80]. However, large numbers of transformants have been made using AtMT and screened on plants.

The current "record holders" in terms of strain numbers are C. higginsianum, a pathogen of Cruciferae species, and C. gloeosporioides, a pathogen with a wide host range that includes both monocot and dicot plants. For C. higginsianum three sets of mutants that total more than 21,000 T-DNA mutants have been isolated and screened on $A$. thaliana [81-84]. These studies both traced the stages during the infection cycle in which mutants were blocked in causing disease, and went on to identify 17 new pathogenicity genes for this species. For C. gloeosporioides two screens on more than 14,000 T-DNA strains in total have been conducted $[85,86]$. The recent study by $\mathrm{Wu}$ et al. used an in vitro screen to identify genes required for the production of asexual spores that are required to establish disease to identify 11 candidates for genes required for conidiation [85]. Cai et al. generated more than 4000 insertional strains and screened them on detacted rubber tree leaves, to identify 16 genes required for pathogenicity [86]. In addition to random insertional mutagenesis, AtMT can be used in Colletotrichum species to make targeted gene replacements, and this has been enhanced by the isolation of mutants in the Ku genes for the non-homologous end joining DNA repair pathway [82]. This pathway is involved in the ectopic insertion of DNA into fungal genomes, and thus pathway mutants have a high proportion of targeted gene replacement events after transformation.

An example of convergent discoveries by using AtMT in Colletotrichum species has been the recent independent identification of T-DNA insertional mutants in the same signaling pathway in C. higginsianum [87] and $C$. orbiculare [88]. Both studies found insertions in components of the Regulation of Ace 2 and Cellular Morphogenesis (RAM) pathway, a complex of two kinases and associated proteins that controls cell morphology in fungi. With six components, collectively this provides a large target for T-DNA insertions, and as discussed under the section on the basidiomycete $C$. neoformans, the same pathway was also first identified as impacting multiple functions in this human pathogenic yeast from T-DNA insertional mutants [89].

\section{Leptosphaeria maculans}

A plant pathogen that is not included in the "top 10" [30] list is Leptosphaeria maculans (Dothideomycetes), in which substantial use of AtMT has been made as an insertional mutagenesis tool. L. maculans is a phytopathogen capable of attacking cultivated Brassicas such as $B$. napus, $B$. rapa, $B$. juncea, $B$. oleracea as well as numerous wild Cruciferae species [90].

Leptosphaeria maculans was among the first ascomycetes genetically transformed, by PEG-mediated transformation of protoplasts [91]. The first forward genetic screen in $L$. maculans was undertaken using REMI, a method that has been discussed above in sections "Advantages of AtMT over other transformation techniques" and "Pyricularia oryzae". A screen of 516 transformants identified 12 loss of pathogenicity mutants [92]. An evaluation of 47 randomly selected insertional mutants revealed complex patterns of insertions with 31 containing insertions at multiple loci, 12 with single loci insertions of multiple copies of plasmid and only 4 had single copies of the insertion plasmid, aptly illustrating the drawbacks of REMI discussed previously. PEG-mediated transformation was also used successfully to deliver gene disruption cassettes to L. maculans resulting in the disruption of genes, although at frequencies as low as less that $0.25 \%$ of transformants [93].

AtMT was first shown to be effective in $L$. maculans with the successful knockout of genes encoding an ATP binding cassette transporter and two-component histidine kinase [94]. The frequency of gene deletions achieved in this study was still less than 1 in 140, therefore a negative selectable marker was developed whereby two copies of a thymidine kinase gene from the herpes simplex virus were amended to the ends of the deletion vector. Transformants arising through ectopic integration of plasmid DNA would still contain the thymidine kinase negative selectable marker and should not grow in the presence of thymidine analogues fluorodeoxyuridine or trifluorothymidine. This strategy increased the rate of homologous integration up to 1 in 30.

The greatest impacts of AtMT in L. maculans are its use as a forward genetics tool for random mutagenesis and a transformation tool to deliver gene constructs that manipulate the expression of endogenous fungal genes. In comparison with other fungi discussed in this 
review, the forward genetics studies are smaller in scale and highlight some of the unusual events that can occur when a T-DNA is inserted into a host genome. For example, in the first forward genetic approach published, 91 transformants were screened to identify one reduced pathogenicity mutant with a T-DNA insertion in the promoter region of two divergently described genes that resulted in increased expression of both genes and rendered the transformed strain "uncomplementable" [95]. To circumvent this problem AtMT was used to recreate this state of overexpression in new mutant strains, overexpressing both genes individually or together, and this led to the finding that overexpression of a maleylacetate reductase results in loss of pathogenicity in L. maculans. Interestingly this effect of T-DNA insertion altering the gene expression or transcript stability in unexpected ways has since been reported on several occasions [96, 97]. In two independent studies, the T-DNA inserted into the $3^{\prime}$ regulatory sequences of genes thereby altering the length and/or stability of transcripts, and resulted in the discovery of the IFRD gene, which is important for cell wall integrity, conidial germination and pathogenicity, and the $c p c A$ gene, which is responsible for regulating the production of amino acids during starvation growth. In both of these studies where the insertion of T-DNA resulted in a complex phenotype, AtMT was also used to deliver RNA interference constructs to create isolates with reduced expression of the gene of interest.

Blaise et al. [98] and Bourras et al. [99] published the largest and most extensively characterized forward genetic screens conducted in L. maculans to date. Blaise et al. found that 53 transformants out of 1388 tested had altered but reproducible pathogenicity phenotypes, ranging from lost, reduced, delayed and growth condition dependent defects. By genetic crossing of 12 mutants they could show that the T-DNA insertion was linked to the loss of pathogenicity in only $50 \%$ of the cases, thus highlighting a limitation of $A t \mathrm{MT}$. They retrieved left border sequences from 135 randomly selected transformants and observed a trend towards integration into gene rich regions with a possible bias towards regulatory or intergenic regions. These findings were substantiated in much greater detail by Bourras et al. [99] whereby 400 border sequences were obtained through thermal asymmetric interlaced (TAIL)-PCR and primer walking, thus identifying 318 single locus T-DNA integration events. With the backing of an annotated genome, the authors were able to confirm that $97 \%$ of T-DNA integrations were mapped into GC-rich and transcriptionally active regions of the genome. There was also some evidence of chromosomal bias with statistically more T-DNA insertions in chromosomes 5 and 10 and less in chromosome 18 than would have been predicted for completely random insertions. A detailed examination of insertions into the gene-rich areas showed that there were more insertions into gene regulatory regions and introns than would have been expected under a random integration hypothesis, and less insertions than expected in intergenic regions and exons. Futhermore, a comparison of the promoter sequences of targeted genes with the T-DNA left border flanking sequence revealed 5 bp long consecutive stretches of homologous sequences, termed microhomology domains, consistent with the integration of T-DNA into the L. maculans genome via a microhomology-mediated end-joining pathway. What is readily apparent from these studies is that T-DNA insertion into the L. maculans genome does not necessarily result in gene disruption or loss of gene function, and extreme truncations and chromosomal translocations can occur [100].

Given that all known genes encoding effectors, which are small secreted proteins involved in plant pathogenhost recognition, characterized in L. maculans to date are located in AT-rich regions of the genome and if one would assume that genes required for infection are lowly expressed in culture [101], the efficiency of AtMT to target pathogenicity genes is questionable. However, the ease with which $L$. maculans can be transformed via AtMT offers realms of opportunities for other forward genetics screens and the delivery of genome tailoring enzymes in the future. Furthermore, AtMT is used to deliver RNA silencing constructs into L. maculans, and can be used to confirm the functions of effector genes [102].

\section{Histoplasma capsulatum}

The ascomycetes also include a number of human pathogenic species, such as Histoplasma capsulatum (Eurotiomycetes), the etiologic agent responsible for histoplasmosis or "cave disease". It is an infection of the lungs normally arising through inhalation of fungal spores and is especially common in immunocompromised patients. $H$. capsulatum is a thermally dimorphic fungus characterized by two different growth forms. The saprophytic form of the fungus grows as a filamentous mold with aerial hyphae in the environment (especially in soil that contains bird or bat droppings) whence spores can become airborne and inhaled by people; the person's body temperature allows the pathogen to grow into the next stage of its life cycle that consists of a yeast that can infect lungs, or it can travel to lymph nodes and spread through the bloodstream to other parts of the body, such as the central nervous system [103]. H. capsulatum can also cause significant mortality and morbidity in healthy hosts with approximately 25,000 estimated life-threatening infections per year in countries where the fungus is endemic [104]. 
Molecular research on $H$. caspulatum has been performed for many years, and technological developments were reviewed more than a decade ago [105]. Electroporation was the most successful technique for transformation compared to biolistic and lithium acetate/ PEG-mediated transformation for efficiency and reliability, although episomal plasmids and multiple random insertions of heterologous DNA limited the exploitation for its use in functional genetics studies despite several optimization attempts [106]. As a further step toward the development of reliable and efficient molecular tools, a protocol based on AtMT was developed for H. capsulatum and the related dimorphic species Blastomyces dermatitidis [107]; since then, AtMT protocols have been developed for other dimorphic fungi such as Coccidioides spp., Sporothrix schenkii, Paracoccidioides brasiliensis and Talaromyces (Penicillium) marneffei (see review [108]). We focus attention on AtMT of H. capsulatum and the main discoveries arising from use of this technique.

Sullivan and colleagues [107] compared the feasibility of AtMT using two different selection markers, the native $H$. capsulatum URA5 gene, and the $h p h$ gene (for hygromycin resistance) placed under the control of the $A$. nidulans gpd promoter and trpC terminator. In both $H$. capsulatum and $B$. dermatitidis, a 5- to 10-fold higher transformation efficiency was achieved using the selection for uracil prototrophs. Moreover, T-DNA insertions were always found in the host genome with more than $80 \%$ of transformants obtained bearing single T-DNA insertions; however, a small percentage of multiple copies of T-DNA, small rearrangements or deletions, and integration of plasmids regions beyond the T-DNA borders were also observed. As an insertional mutagenesis tool, AtMT works most effectively when the DNA is transformed into uninucleate cells, which are more easily obtained for $H$. capsulatum than for $B$. dermatitidis.

Following this first report of AtMT in these dimorphic species, other promoters (i.e. from TEF1), selection markers or reporter genes (i.e. GFP, $B L E$ ), and other transformation parameters were optimized [109]. For example, Marion et al. [110] optimized AtMT and went on to identify $H$. capsulatum loci that impact the production of cell wall $\alpha-(1,3)$-glucan, based on a simple and effective visual screening: wild-type strains of $H$. capsulatum have a visibly "rough" colony morphology on culture plates, while mutants that lack $\alpha-(1,3)$-glucan have a "smooth" colony appearance. Beside AGS1, which was already characterized as important for cell wall construction in $H$. capsulatum, two novel genes ( $A M Y 1$ and UGP1) required for $\alpha$ - $(1,3)$-glucan biosynthesis were identifed, of which $A M Y 1$ was also found to be required to kill macrophages and to colonize murine lungs [110].
The dimorphic transition is key for pathogenicity, but until 2008 little was known about what genes regulated the transition. Sil and colleagues identified AtMT mutants that were unable to make the transition from the filamentous (fuzzy colonies) to the pathogenic yeast form (smooth colonies) under temperature shift from room temperature to $37^{\circ} \mathrm{C}[111,112]$; the mutated genes were named RYP1, RYP2 and RYP3 from "required for yeast phase growth". Subsequent studies demonstrated that these genes encode a connected network of transcription factors that regulate each other and target common genes to activate a transcriptional program that is required for cell shape changes and expression of virulence genes in response to host temperature in $H$. capsulatum [113].

AtMT was also used to identify genes of $H$. capsulatum required for intracellular growth and virulence by assessing the survival rate of T-DNA mutants within macrophages, which led to the identification of the genes VMA1 and HSP82, both crucial for virulence in an pulmonary murine model for histoplasmosis [114, 115]. More recently, in another AtMT screen, Isaac and colleagues revealed a mechanism of evasion of $H$. capsulatum from macrophages that involves the protein calcium-binding protein $\mathrm{Cbp} 1$, which had been previously characterized [116] and also identified by another group using AtMT coupled with reverse genetics and PCR screening [117]. In their screen the authors identified three independent $c b p 1$ mutants that grew at wild type level within macrophages but failed to elicit host-cell death; $c b p 1$ mutants also showed attenuated virulence in an animal model, thus suggesting a key role for Cbp1 in favoring dissemination of the fungus in the host through a mechanism that seems to be specific for $H$. capsulatum and related dimorphic fungi.

\section{Other pathogenic ascomycetes}

Whilst AtMT has had considerable success in studying gene function in plant pathogens, it has also been deployed in other pathogenic fungi, in some cases to investigate the wider functional applicability of the virulence factors first characterized in other fungal species.

Amongst insect pathogenic fungi, Metarhizium spp. (e.g. [118]), Beauveria spp. (e.g. [119]) and Lecanicillium lecanii [120] (all three in the Sordariomycetes) have been transformed by this method, with a sizable AtMT T-DNA mutant collection generated in B. bassiana [121]. In Metarhizium spp, targeted gene disruption has been reported using this approach to characterize genes such as the non-ribosomal peptide synthase needed for serinocyclin synthesis [122] and further developed for high throughput gene disruption [123].

Amongst mycopathogenic fungi, Coniothyrium minitans (Dothideomycetes), a fungal parasite of the plant 
pathogen Sclerotinia sclerotiorum, has been successfully transformed by AtMT [124], and in the mushroom pathogen Lecanicillium fungicola (Sordariomycetes), the method has been used for targeted disruption of cell wall degrading $\beta-1-6$ glucanase [125] and the Pmk1-like MAP kinase [126], with mutation of the latter gene somewhat surprisingly not having any impact on virulence.

\section{Phylum Basidiomycota}

Basidiomycetes are distinguished morphologically by their sexual spore formation, produced on the ends of club-shaped cells (basidia) in which meiosis has taken place. The phylum is divided into three major subphyla, the Agaricomycotina, Pucciniomycotina and Ustilaginomycotina (Fig. 2). While some species of basidiomycetes (e.g. U. maydis, Coprinopsis cinerea or C. neoformans) have served as models for aspects of plant pathology, medical mycology, fungal or general biology, compared to ascomycetes relatively less was known about gene functions in the phylum prior to the advent of AtMT.

It was fortuitous that the two main model basidiomycetes that had been preferred for classical Mendelian genetics, the inkcap toadstool C. cinerea (Agaricomycotina) and maize smut $U$. maydis (Ustilaginomycotina), both proved to be readily amenable to protoplast-based transformation methods. These species provided reliable and reproducible starting material for protoplasting, in the form of asexual ooidia for $C$. cinerea and yeast-like sporidial growth for $U$. maydis. Both species gave good yields of transformants, and $U$. maydis had the additional benefit of having both integrative and autonomous transformation vectors, and a very efficient homologous recombination system allowing easy gene targeting. The early progress achieved in these species encouraged researchers to investigate the tractability of other basidiomycetes, but difficulties were often encountered when attempting to transfer the methods developed in these models to other species. In particular the absence of asexual spores in the majority of species in the Agaricomycotina meant that protoplasting had to be performed on highly variable mycelial cultures, and the obligate pathogens such as the Pucciniomycotina species causing rusts were largely ignored due to the inherent problems in only being able to work with such species in planta.

\section{The mushroom-forming species of Agaricomycetes}

Historically the transformations of species in the Agaricomycetes (Agaricomycotina) were often of very low efficiency, variable in terms of success, and few suitable vectors had ever been developed. Indeed, for the cultivated button mushroom Agaricus bisporus, only one lab was successful in protoplast-based transformation. The report in 1998 of transformation of seven fungi
[4], including A. bisporus, was therefore met with great excitement by the basidiomycete community and was followed by a flurry of papers on different species, although often without the high transformation frequencies seen in ascomycetes. A number of confounding factors then became apparent that help explain why the initial transformation attempts were often without success.

The key breakthrough came when Chen et al. [127] demonstrated that whilst most tissues of A. bisporus would only yield low transformation efficiencies, the use of gill tissue excised from fruiting bodies immediately prior to veil-break gave high efficiencies. A similar situation occurs in the important forestry pathogen Armillaria mellea, where the most amenable tissue for transformation is basidiospores collected from either wild-grown fruiting bodies [128] or laboratory-raised fruiting bodies [129]. These studies flag the importance of selecting the appropriate developmental stage of fungal material, since not all stages are equally amenable to transformation.

Another breakthrough in the transformation of the Agaricomycetes came with the observation that transgenes often needed to include an intron, ideally at the $5^{\prime}$ end of the gene. This proved to be important whether the selection or antibiotic resistance cassette was introduced via protoplasts or via $A t \mathrm{MT}$, and impacted both on choice of reporter genes and on some of the selectable markers [130]. This requirement varies from species to species, and indeed from gene to gene. For instance it is fortuitous that it is not normally required for the function of the hygromycin resistance gene typically used in initial selection of transformants, but is needed in some cases for successful deployment of the gene conferring resistance to phleomycin [131].

The choice of promoters to drive transgene expression is important because this determines when, where and if the transgene is expressed. Not all fungal promoters are active when transferred into the genome of a related species and this had to be assessed on a case-by-case basis, which added constraints to the wider utility of some of the vectors [132]. Examples from the Agaricomycetes illustrate this point. Whilst the A. bisporus gpd promoter showed a reasonable spectrum of activity in other fungi, there were instances where it was not very successful (e.g. $[133,134])$ and there was no readily apparent pattern to explain this. This is in contrast to many of the ascomycete vectors in common use where promoters such as $\operatorname{trp} C$ or $g p d A$ from A. nidulans have been used in other ascomycete species over wide evolutionary distances. Effective promoters that function a cross phyla are less common in Agaricomycotina, but it is perhaps noteworthy that the DNA immediately to the $5^{\prime}$ of the start codon of the C. neoformans actin gene was successful in driving 
hygromycin resistance in Hypsizigus marmoreus, Flammulina velutipes, and Grifola frondosa, suggesting that this promoter may have broad utility [135]. Curiously, RNA-seq data indicate that this DNA is a combination of promoter and the $5^{\prime}$ untranslated region, with that region containing an intron that is spliced in C. neoformans [136].

To add further complexity to the deployment of AtMT in basidiomycetes, Kilaru et al. [131] highlighted that two slightly different forms of the hygromycin resistance cassette were in common usage, and that these gave very differing transformation efficiencies in a species-specific manner. Once all these factors-cell material, introns in markers, promoters and cassettes-were fully appreciated and factored into planned investigations, it has become far easier to transform basidiomycetes. This has allowed a wide set of studies to be undertaken on diverse aspects of basidiomycete biology.

To date, the transformation experiments on the Agaricomycetes have primarily focused on species with either edible fruiting bodies or where there is a biotechnological application, and publications have focussed on methodological development. This methodology has since been deployed to help assess expression patterns using reporter genes and now mutant screens in other species such as Laccaria bicolor [137]. One interesting approach has been in modifying the stress tolerance in fruiting bodies, for example in conferring cold-tolerance to the paddy straw mushroom Volvariella volvacea [138]. In other cases, the yield of pharmaceutically relevant compounds, such as ganodermic acid in Ganoderma lucidum [139], clavaric acid in Hypholoma sublateritium [140] or various triterpenes in Antrodia cinnamomea [141], has been enhanced as a result of AtMT by overexpression of a core biosynthetic gene. One drawback to using AtMT for overexpression is that it usually only delivers a single copy of the transformation construct and may not achieve as high a titre of the desired compound. In contrast, protoplast-mediated events often result in multicopy integrations, delivering a wider range of expression levels, with some transformed strains having very high titre, which can be beneficial to create high expression strains.

Perhaps the most powerful application of AtMT is in delivering constructs to effect gene silencing. This is of particular interest in basidiomycetes as the hyphae, which are often the starting material for transformation, are often maintained in a dikaryotic state, precluding the easy use of gene disruption (which requires nuclear integration of a construct) to assess gene functionality. Because post-transcriptional gene silencing operates within the cytoplasm, it has a dominant effect and thereby can cause a phenotype in the mutant lines despite their heterokaryotic state. Effective gene silencing has been deployed in a number of basidiomycetes, including the important mycorrhizal symbiont $L$. bicolor $[142,143]$ and in A. bisporus where it has been deployed to identify core synthetic genes and also the proteases involved in nutrient acquisition [144, 145].

Transformation, however, is still often challenging. While some species are naturally amenable to gene targeting/deletion via homologous recombination, and others can be made amenable by use of mutants in the non-homologous end joining pathway such as KU70 mutants (e.g. C. cinerea [146]), many still have no reports of successful gene targeting. The recent high profile report of successful deployment of CRISPR/Cas in A. bisporus [147] may serve to overcome these issues, and we would expect the Cas proteins and guide RNA construct(s) to be deployed using Agrobacterium-vectors given how successful they have been in the Agaricomycetes in broadening the range of species amenable for transformation.

\section{The C. neoformans species complex}

Cryptococcus species are major fungal pathogens of humans within the Agaricomycotina [104], divided into serotypes, varieties, two species $C$. neoformans and $C$. gattii, and the most recent classification splitting C. neoformans into two species and C. gattii into five species [148]. All species cause disease in humans and animals, and among them, C. neoformans (sensu stricto) is the one most commonly isolated in clinical settings [149]. In immunocompromised individuals the fungus infects the lungs, crosses the blood-brain barrier and invades the cerebrospinal fluid, causing fatal meningitis if untreated [150]. The disease causes hundreds of thousands of deaths globally each year [151].

Molecular studies of $C$. neoformans benefit from effective tools for random and targeted mutagenesis, conditional gene expression, gene editing and protein localization. Moreover, approaches of functional genetics were dramatically streamlined by the availability of genome sequences for several Cryptococcus species since the early 2000s (see review [152]). Electroporation and biolistic methods were the first transformation methods developed for C. neoformans $[153,154]$ and were employed for delivering episomal plasmids into the fungus, heterologous gene expression and gene-targeted mutagenesis. As tools for random insertional mutagenesis they have been used to study several biological processes in C. neoformans: examples are the identification of the essential gene $C A M 1$ encoding calmodulin through fortuitous insertion of a marker in the $3^{\prime}$ UTR of the gene yielding a temperature-sensitive mutant [155], and an insertion in a chloride transporter required to 
balance ions for the synthesis of the virulence factor melanin [156]. Although effective as transformation tools, both electroporation and biolistics are characterized by the high rate of genetic instability of transformants probably due to transgenes not integrating into the host genome, with reports ranging from 70 to $85 \%$ of such transformant being unstable [149]. Therefore electroporation and biolistics are mainly used for the generation of targeted mutants through homologous recombination $[153,154]$.

AtMT was first used for the C. neoformans/C. gattii complexes in the early 2000s $[157,158]$. The selective markers used included those that confer resistance to nourseothricin, G418 and hygromycin [157, 159], which have been extensively used for AtMT functional genetics studies. Other plasmids for AtMT of C. neoformans include those enabling the fusion with genes to assess protein localization and conditional promoters. From these early reports, the high potential of AtMT became clear when compared to electroporation and biolistic transformation, with the advantages of having a higher rate of transformation and stability of the T-DNA insertion (close to 100\%). One relevant limitation or feature of AtMT for Cryptococcus is that it has not yet been successfully deployed for targeted gene replacement [158], making it different from most other fungi.

AtMT has featured in more than 30 studies on Cryptococcus species, many of which have used the T-DNA insertions as a mutagenic tool in forward genetics. As such, AtMT has been valuable for the identification of Cryptococcus genes that are not conserved in S. cerevisiae, which represents a reference organism in fungi and thus a starting point for the identification of C. neoformans orthologs whose specific function is in general assessed by targeted mutagenesis. However, some of the most significant discoveries in Cryptococcus species have been made by extending the capabilities of AtMT beyond just an insertional mutagenesis tool for wild type strains. Hence, an additional focus is placed on these species in the following sections.

To gain insight about C. neoformans pathogenesis, T-DNA mutant screens have been performed using surrogate markers for virulence, such as changes in the production of the pathogenicity factors melanin and capsule, and the ability to grow at human body temperature $\left(37^{\circ} \mathrm{C}\right)$. Screens to identify the molecular basis of melanin biosynthesis exploit the presence of visible dark pigments produced by $C$. neoformans on media containing L-DOPA or other phenolic precursors on which melanindeficient mutants are easily identified as white or pale colonies. This screen was performed as a proof-of-principle in the development of $C$. neoformans AtMT with the identification of the genes $L A C 1$ and $C L C 1$, encoding the main laccase involved in melanin biosynthesis and a putative voltage-gated chloride channel, respectively [157]. In a subsequent screen the same authors identified three more independent lac1 mutants (Fig. 4a). Other mutants with melanin defects as well as mutants unable to grow at human body temperature were also identified $[159,160]$. Successful identification of T-DNA mutants impaired in capsule production was performed by visual analysis of colony morphology or by selecting mutants unable to use heme, leading to the identification of the CAP60, ARF1 and VPS23 genes [89, 161].

Beside in vitro studies, a method to identify $C$. neoformans genes required for virulence in vivo used signature tags that were incorporated into the T-DNA molecules. Pools of signature-tagged T-DNA mutants were used for murine pulmonary infection experiments, and once the disease developed and the mice sacrificed, the reduction of the signature tag signal in the population of strains recovered from the mouse lungs indicated strains with possible reduction in virulence. This approach allowed the identification of a T-DNA mutant with reduced numbers of cells from the lungs. The impaired gene, ENA1, that encodes a putative ion transporter was then shown to be required for virulence in conventional virulence assays with an independently created gene deletion strain [160]. Remarkably, this application of AtMT was the first forward genetic screen in a eukaryotic human pathogen that used virulence in animals as the phenotype. In contrast, such loss-of-virulence/pathogenicity screens have been extensively exploited with plant pathogenic fungi, as discussed above.

The application of $A t \mathrm{MT}$ has also greatly contributed to decipher the mechanisms of light responses in C. neoformans and more broadly the fungi. While the $C$. neoformans $B W C 1$ gene encoding the blue light sensor was identified through searches of orthologs, other signaling components could not be identified through bioinformatic searches. Thus, a haploid strain was modified to become self-filamentous by the introduction of a construct to express the opposite mating type homedomain protein, and then used in a T-DNA insertional mutagenesis screen to find mutants with impaired sexual filamentation. One strain whose filamentation was not repressed when exposed to either light or dark had an insertion in the $B W C 2$ gene: the Bwc2 protein was then shown to directly interact with Bwc1 and be involved in the light responses during mating, and UV resistance. Furthermore, it was required for virulence [162]. The $B W C 2$ gene was independently identified by other investigators in subsequent AtMT screens [163, 164], indicating a level of saturation in T-DNA mutant screens in this organism. Last, the downstream factor responsible for the UV sensitivity phenotype in $b w c l$ or $b w c 2$ mutants was also 
a
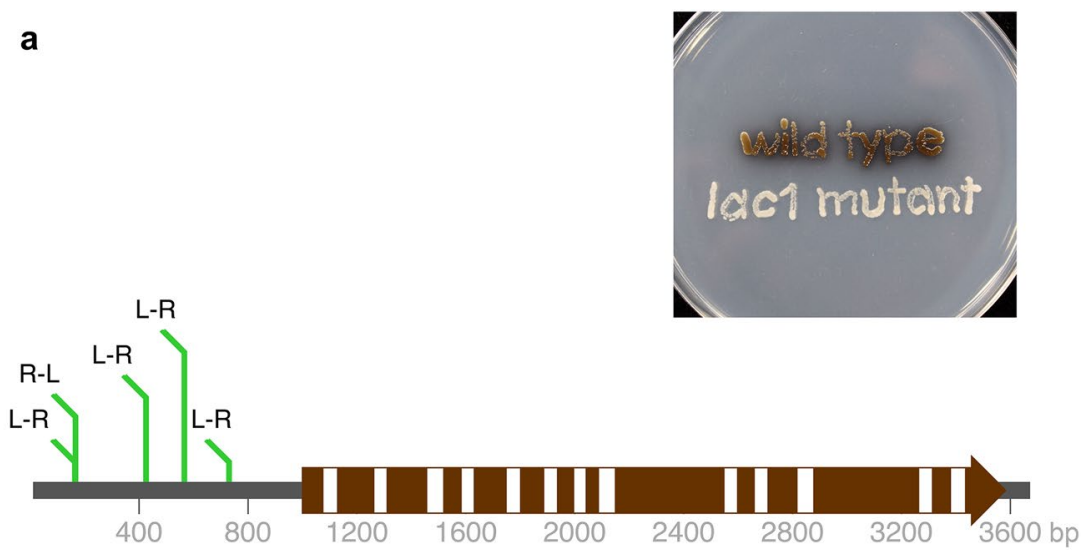

b

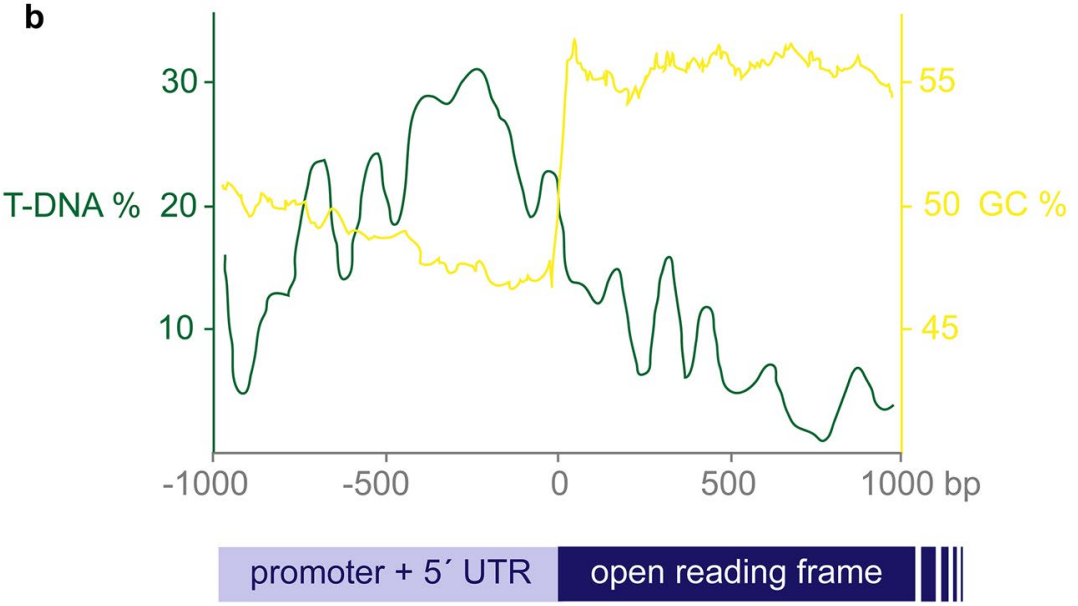

Fig. 4 Two examples of T-DNA insertion bias into the $5^{\prime}$ non-coding (or flanking) regions of the genes in Cryptococcus neoformans (a basidiomycete yeast and human pathogen) and Pyricularia oryzae (a filamentous ascomycete and plant pathogen). a Example of a single gene in C. neoformans targeted by T-DNA insertion on five occasions $[157,159,160]$ causing loss of pigmentation. A schematic drawing of the $L A C 1$ gene represented by an arrow shows coding regions as brown boxes, introns as white boxes and upstream and downstream non-coding sequences as a grey line. T-DNA insertions from five independent transformation events each causing loss of pigmentation all lie within the upstream region, with none to date in the coding region. $R$ and $L$ refer to the left and right border and the relative positions of these when the T-DNA inserted; note that the same site is targeted by two independent insertion events in opposite orientation. The plate shows $C$. neoformans wild type and one of the T-DNA insertional mutants growing on medium containing the substrate for laccase, L-DOPA. $\mathbf{b}$ Example of insertional bias of T-DNA into the genome of $P$. oryzae transformants. Results and figure are modified from Ref. [40]. An analysis of the distribution of 799 insertion sites mapped into 50 bp windows illustrates a twofold higher insertion frequency in promoter or untranslated regions compared to coding regions. This is even more striking in that such regions have a higher proportion of AT nucleotides while in P. oryzae T-DNA insertions are preferentially into higher GC content DNA

identified as a UV sensitive T-DNA insertional mutant, in the gene encoding the Uve1 endonuclease required for repair of UV damage [165].

Using similar assays, AtMT has been extensively used to identify genes required for mating and the transition from the yeast to hyphal form. A forward genetic screen performed on a hyperfilamentous strain derived from Cryptococcus deneoformans (previously C. neformans var. neoformans) isolated seven mutants unable to produce filaments during the $\alpha-\alpha$ mating reproduction process (a homothallic mating system observed within the Cryptococcus clade). One mutant had a T-DNA insertion in the transcription factor gene $M A T 2$, a key regulator of the sexual reproduction pathway essential for pheromone sensing, responding and cell fusion [166]. Two other independent screens using the same hyperfilamentous strain identified a new transcription factor, $\mathrm{Znf3}$, that governs sexual reproduction though a MAT2-independent pathway, and Spo11 and Ubc5 proteins that are essential for sporulation [164], and the long non-coding RNA RZE1, which controls yeast-to-hypha transition through regulating the key morphogenesis regulator Znf2 [167]. Filamentation can still occur in the mat2 $\Delta$ deletion mutant, and recently additional components 
required for filamentation were identified by a screen of 77,000 insertion mutants in a mat $2 \Delta$ background [168]. STE50 was identified as being required for all steps of monokaryotic fruiting and sexual reproduction, i.e. from response to pheromone to production of hyphae [169]. In these studies many other mutants with impaired mating and filamentation defects have been identified, and they include both previously characterized genes (e.g. $Z N F 2$, $M A T 2, S T E 7$ and $B W C 2$ ) and those of unknown function that at the present are subject to further studies.

AtMT has also been used for new drug target discovery. In two studies $A t \mathrm{MT}$ insertional mutagenesis was used to identify genes essential for viability. In the first it was performed on a diploid strain derived from C. neoformans, using Mendelian genetic segregation analysis on the haploid spores arising after meiosis [170]. In the second, a haploid strain was mutagenized by the introduction of a regulatable promoter within the T-DNA [16]. The essential genes identified are potential targets for new antifungal drugs.

Additional important discoveries in C. neoformans based on AtMT include the identification of the CTR2 gene required for evasion of macrophages [171], the RAM pathway components that confer altered colony morphology and control cell polarity [89], genes required for growth under hypoxic conditions [172], and the basidiomycetous-specific gene $R R A 1$ involved in the RIM101-mediated alkaline responses [173].

\section{Pucciniomycotina}

The Pucciniales that cause rust diseases The rust-disease fungi represent the largest group within the Pucciniomycotina with about 7000 species that are obligate pathogens of many crop plants and trees, and for this reason they represent the most economically important group in this clade [174]. It is extremely difficult to conduct molecular studies and functional characterizations of genes in Pucciniales fungi for several reasons. First, as obligate biotrophic pathogens they cannot be cultured on artificial media; second, most of their life stages are dikaryotic, including the urediniospores that are commonly used in laboratory experiments; third, the need of a reliable transformation system that allows stable ectopic integration of the exogenous DNA; last, the lack of gene markers that force the selection of clear phenotypes only when the rust fungus is inoculated inside the host. Hence, the first and few reports on functional genetics consist of transient transgene expression achieved through biolistic transformation. However, transformation efficiencies were low and the transformants obtained were unstable, with two rare exceptions in Puccinia triticina [175].

The only successful and stable transformation experiment was in the flax rust fungus Melamposora lini using
AtMT [176]. The approach was exceptionally innovative. The genetic marker for selection was developed based on a previous finding that an avirulence gene of $M$. lini (AvrL567) when mutated can lead to disease in flax cultivars with a specific resistance gene $(L 6)$. Lawrence et al. used a hairpin antisense structure to silence the AvrL567 avirulence gene and performed AtMT of $M$. lini within the plant itself, i.e. within stems of a plant cultivar with no resistance genes that had been inoculated 5 days before with a $M$. lini isolate bearing homozygous copies of the AvrL567 gene [176]. Candidate silenced urediospores were collected at different time points from these plants and inoculated into a cultivar containing the $L 6$ resistance gene, thus allowing the transformants to be selected by their ability to cause lesions. $M$. lini isolates that were able to cause disease were obtained, and molecular analyses confirmed stable integration of the T-DNA and robust silencing of the native AvrL567 gene. Despite this elegant strategy, functional genetics through $A$. tumefaciens transformation-mediated gene silencing has not taken place yet in rust fungi and the work of Lawrence and colleagues is still the only report published [176].

Microbotryum lychnidis-dioicae The Pucciniomycotina includes other plant pathogens, such as M. lychnidis-dioicae (M. violaceum sensu lato) that causes anther smut of plants in the Caryophyllaceae family. M. lychnidis-dioicae is a dimorphic non-obligate biotrophic fungus that has been intensively studied both at the genomics and genetics levels (see review [177]). It is considered a model system in non-agricultural settings and ecological studies, offering alternatives to study host-pathogen interactions in diverse host environments. Further, M. lychnidis-dioicae has been used as a model for studying the evolution of sex chromosomes in fungi, and it was the first fungus in which heteromorphic mating type chromosomes were described [178].

The potential of the resources that have been generated has not been fully exploited at the level of gene functions due to the lack of a reliable transformation system, despite early and apparently successful attempts. In 1989 Bej and Perlin reported the first transformation of $M$. lychnidis-dioicae [179] where they used lithium acetate and PEG to deliver into both protoplasts and intact cells a plasmid containing the $h y g B$ gene as the selective marker. Transformation efficiency was high and the exogenous DNA was integrated stably into the nuclear genome. Subsequently, the same authors reported the successful transformation of $M$. lychnidis-dioicae using bacterial DNA conferring resistance to neomycin [180]. Despite the positive outcome achieved, these techniques were not reproducible by other researchers, and transformation attempts using biolistics were unsuccessful [177]. 
By exploiting the newly acquired genomic and transcriptomic data for M. lychnidis-dioicae, a robust transformation system based on AtMT has recently been developed [181]. The selection markers delivered through AtMT consist of endogenous promoters of the most highly expressed genes under different phases of the fungal lifecycle, as assessed by previous transcriptomic data [182], fused with the HYG2 gene alone or in combination with $e G F P$. Stable and random integration of the T-DNA in the M. lychnidis-dioicae genome was achieved, and also expression/over-expression of inserted genes, corroborating transcriptomic data. Although this is the only report of stable transformation in M. lychnidis-dioicae, the authors showed its potential as an insertional mutagen, thus opening a new field of functional genetics in this fungus. Currently further molecular tools, such as the overexpression of a heterologous marker using a native promoter as the driver and a targeted knockout system, are under development [177].

Red yeasts The red yeasts in the Pucciniomycotina are a polyphyletic group that included the four genera Sporobolomyces, Sporidiobolus, Rhodotorula and Rhodosporidium, but in a recent reclassification most of the Sporidiobolus and Rhodosporidium teleomorphic species were grouped with their anamorphic counterparts Sporobolomyces and Rhodotorula, respectively, and a new genus (Rhodosporidiobolus) was created [183]. Compared to ascomycetous yeasts, whose importance in biotechnology has been known since ancient times for fermented beverages and food, basidiomycetous red yeasts have been relatively understudied in terms of their potential importance in biotechnology, agriculture, food processing, and environmental impact. The last few decades have revealed that these yeasts have a multitude of unique beneficial attributes, which include the production of secondary metabolites such as carotenoids and fragrances, sources of enzymes important in pharmaceutical production and chemical syntheses, biodegradation of pollutants and mycotoxins, antagonistic activity against plant pathogenic fungi, and high levels of lipid synthesis for biofuel production [184].

Gene functions in red yeasts were unexplored, with a single report of transformation in 1985 and nothing afterwards until 2010 [185]. In 1985 Rhodosporidium toruloides was transformed with a protoplast-lithium acetate/PEG approach: although transformation was successful, it yielded a very low number of transformants $\left(\sim 10^{3} / \mu \mathrm{g}\right.$ DNA $)$ and the majority of which were unable to retain the introduced exogenous DNA. Since 2010 there has been a drive to generate transgenic strains by two methods, biolistic and Agrobacterium T-DNA delivery.
Initial AtMT attempts in red yeasts were unsuccessful due to the lack of Pucciniomycotina-specific gene markers and the capability of some species to become spontaneously resistant to the common drugs used in transformation protocols in the Agaricomycotina and Ustilagomycotina yeasts. The first successful AtMT of red yeasts was for Sporobolomyces sp. IAM 13481 [186], whose draft genome sequence and annotation had been released by the Joint Genome Institute (JGI). The strategy employed was based on the use of the endogenous Sporobolomyces sp. IAM 13481 URA5 and URA3 genes as selective markers to restore prototrophy in ura 5 or ura3 auxotrophs that were isolated as spontaneous mutants resistant to 5-fluoroorotic acid [186]. However, plasmids developed for Sporobolomyces were not effective for other Pucciniomycotina species, and to fill this gap several binary vectors were generated with other selective markers. These include the URA5 and URA3 genes of Rhodotorula graminis strain WP1, the naturally high $\mathrm{G}+\mathrm{C}$ content gene encoding nourseothricin acetyltransferase placed under the control of the promoter and terminator of the tubulin-encoding TUB2 gene [187], and a codon-optimized hygromycin phosphotransferase gene alone or fused with a codon-optimized enhanced green fluorescent protein gene, both placed under the control of endogenous promoter of the GPD1 gene. These latter markers were used successfully to transform $R$. toruloides [188].

The crucial factors for successful transformation of red yeasts were selectable markers that were native copies of genes or including native regulatory elements, appropriate $\mathrm{G}+\mathrm{C}$ content, or recoding the DNA for optimal expression $[187,188]$. Following these key findings, vectors based on other antibiotic-resistance marker genes (bleomycin) and/or other promoters to drive gene expression were also evaluated. These experiments demonstrated multiple stable T-DNA integrations in the genome of $R$. toruloides [189], and showed that strongest heterologous expression was achieved using the constitutive glucose 6-phosphate isomerase promoter [190]. To date AtMT is effective in transforming all the Pucciniomycotina red yeasts tested, which include species within the genera Sporobolomyces and Rhodotorula, and Cystobasidium slooffiae which belongs to a different class (i.e. Cystobasidiomycetes) [187]. The AtMT tools have yielded new insights into genes required for biological processes in the Pucciniomycotina, as illustrated by the following examples.

A T-DNA forward genetic screen was developed with the aim to elucidate the genetic mechanisms behind the ability of red yeasts to resist and degrade the mycotoxin patulin, using Sporobolomyces sp. IAM 13481 as a model 
[191]. Although mutants defective in patulin degradation were not identified (chemical analysis subsequently revealed two independent pathways for degradation in this strain), genes involved in resistance to diverse stresses were identified. The putative functions of the mutated genes as well as the mutant phenotypes correlated with the cytotoxic effects of patulin, allowing the formulation of a hypothesis, which was then substantiated by transcriptomic analyses [192], that Sporobolomyces sp. IAM 13481 activates stress responsive genes to overcome the initial insult caused by the mycotoxin.

In another study, AtMT insertional mutants of Sporobolomyces sp. IAM 13481 were used to investigate the molecular basis of the intriguing mechanism of ballistospore formation and dispersal that is unique to basidiomycete fungi. This property can be evaluated in the laboratory by the production of a mirror image of a culture from one Petri dish onto an uninoculated second dish [193]. The screen of more than 5000 transformants led to identification of 18 mirror mutants unable to shoot spores to produce the mirror image. One mutant bearing a T-DNA insertion in gene PHS1, which encodes 3-hydroxyacyl-CoA dehydratase required for the third step in very long chain fatty acid (VLCFA) biosynthesis, was further subjected to molecular, phenotypic and biochemical characterizations that unequivocally confirmed the involvement of Phs1 and VLCFAs in basidiomycete dispersal through a delay in ballistospore formation. Strikingly, PHS1 is an essential gene in other fungi, and its identification in a Sporobolomyces sp. mutant was fortuitous as the T-DNA inserted within the last intron of the gene and past the essential amino acid residues required for function, which resulted in the production of an altered transcript yet still viable phenotype [193].

An industrial and biotechnological application of gene manipulation by AtMT has been recently reported for $R$. toruloides [194]. In order to achieve a higher rate of lipid production, AtMT was used to generate metabolically engineered strains through a "push-pull" approach for two genes involved in triacylglycerol biosynthesis. A plasmid for AtMT was manipulated to overexpress simultaneously the $A C C 1$ and the $D G A 1$ genes, which encode an acetyl-CoA carboxylase and a diacylglycerol acyltransferase, with the glyceraldehyde-3-phosphate dehydrogenase and the ATP-citrate lyase promoters, respectively. Due to the random integration of the T-DNA into the genome, the transformants showed variability in the production of lipids. However, one transformant had a 2-fold increase of lipids during growth on glucose, compared to wild type.

Beside the random integration of the T-DNA into the host genome, AtMT also can generate targeted gene replacements through homologous recombination in the Pucciniomycotina. This was first demonstrated using a strategy that exploited the change in pigmentation of Sporobolomyces sp. IAM 13481 from red to white when mutating the CAR2 gene [187]. Based on the proportion of white transformants obtained, at least $1000 \mathrm{bp}$ of flanking DNA is necessary to achieve a good percentage $(\sim 6 \%)$ of homologous recombination events. This percentage was about half of that achieved using biolistics transformation, which was included as a comparison since it was known to be effective for target gene replacement in Sporobolomyces sp. IAM 13481 [186, 187]. However, one advantage of AtMT compared to biolistic transformation is that it does not require expensive equipment but the basic resources that are common in a molecular biology or microbiology laboratory. A ku70 $\Delta$ mutant of R. toruloides was generated that showed a drastic improvement of target gene replacement efficiency through homologous recombination, with values ranging from $20 \%$ of deletion mutants obtained using just 100-bp of flanking regions to $\sim 91 \%$ when 1000 bp or 1500 bp were used [195].

A last point worth raising on the role of AtMT in the Pucciniomycotina is that Liu and colleagues used the reliability of the AtMT of $R$. toruloides to develop an inducible promoter system for red yeasts [196]. The DAO1 gene promoter was fused to a codon-optimized luciferase gene, which was then inserted by AtMT at the CAR2 locus of the $R$. toruloides ku70 $\Delta$ strain, allowing the monitoring of the luciferase expression driven by the $p D A O 1$ in the albino mutants. An optimized DAO1 promoter, which contains an intronic enhancer sequence and an artificially created ATG start codon, tightly induces luciferase expression in the presence of $\mathrm{D}$-alanine; conversely, its expression was repressed by L-alanine or glucose and ammonium sulfate. More recently, to further exploit the biotecnological potential of $R$. toruloides, the same authors characterized the promoters of six genes involved in lipid biosynthesis, and identified that the promoter of the perilipin/lipid droplet protein 1 gene ( $L D P 1)$ displays 4- to 11-fold stronger activity than that of the glyceraldehyde-3-phosphate dehydrogenase gene (GPD1), one of the strongest promoters known in yeasts [197].

\section{Ustilaginomycotina}

The third subphylum in the Basidiomycota with a large number of species is the Ustilaginomycotina. These are best known for the species that cause smut diseases of plants. Deployment of AtMT in these basidiomycetes has been patchy. For $U$. maydis and close relatives, where protoplast-based methods have been routine, and gene disruption was already easy, there was no immediate advantage in deploying AtMT. However Ji et al. [198] used $A t \mathrm{MT}$ in $U$. maydis for efficient transformation and gene disruption including on previously frozen cells and 
obviating any need for protoplasting, and Ali et al. [20] used AtMT to deliver large-insert vectors into $U$. hordei. AtMT has also been used to transform Pseudozyma antarctica (Moesziomyces antarcticus), which is an extremophile due to its growth under low temperatures and hence of interest for the potential cold-adapted enzymes it may produce [199].

Recently, AtMT was found to be the only transformation method effective in species of Malassezia [200, 201]. This genus is associated with skin and hair of animals, and represents the main fungal component of the human skin microflora [202]. Despite this high prevalence and links to common human skin diseases, the genus had been poorly studied at the level of gene functions in part due to challenges in culturing the species, all of which are fatty acid auxotrophs. Building on recently developed genomic resources [203], AtMT was optimized for $M$. furfur, M. sympodialis and M. pachydermatis, with cocultivation conditions modified to support higher levels of transformation. A noteworthy aspect of these experiments was high frequencies of targeted gene disruptions ( $>60 \%$ of transformants being knockouts) for two genes in M. furfur [200].

\section{Fungi outside the Dikarya}

The Ascomycetes and Basidiomycetes form a monophyletic lineage in the fungi (Fig. 2), termed the Dikarya due to the presence of two-nucleus cells during the sexual stages of their lifecycle. However, there are at least nine additional lineages that at one point were classified into two groups, the zygomycetes and chytrids, many with limited molecular biology. Given the promiscuity of $A$. tumefaciens-it can transform plants, fungi, oomycetes and human cells $[23,24]$-one application of AtMT that is relatively limited is in the fungal species outside of the Dikarya lineage (Fig. 2).

The Mucoromycota are a large group of species and gene function has been studied through isolation of mutants by chemical mutagenesis screens, and through targeted gene disruption in a few species [204]. AtMT has been applied to a number of these species, and it was first reported in the Mucoromycotina species Rhizopus oryzae [205]. A common limitation is the loss of the transgenes in species such as Backusella lamprospora or Mucor spp. [206-209], which may reflect transient transformation, gene silencing or a foreign DNA surveillance system, or loss over time during passaging of these species that have coenocytic hyphae (without septa) and multinucleate spores. Umbelopsis isabellina is an interesting case, wherein standard $A$. tumefaciens strains used to transform fungi were compared with a strain of $A$. rhizogenes, which is another Agrobacterium species able to transform plants [210]. In this case, the latter bacterial species yielded higher numbers of transformants.

To date, the most successful applications of AtMT in a biotechnology capacity have been on the Mortierellomycotina subphylum, in the species Mortierella alpina, which is a source of polyunsaturated fatty acids that may be beneficial for health. Some fatty acids derived from $M$. alpina are added to infant formula, while others like eicosapentaenoic acid are only otherwise available from fish oil. The initial transformation approaches aimed to modify or increase the fatty acid composition of this fungus [211, 212]. Subsequent studies altered gene expression to change the lipid profiles by overexpressing an $\omega 3$-desaturase enzyme or pathways that alter NADPH levels [213-215].

Other than the Mucoromycota, a chytrid species in the Blastocladiomycota, Blastocladiella emersonii, has been reported as transformed using Agrobacterium [216]. The Glomeromycota are obligate symbionts with the roots of plant species, and are challenging to work with for this reason. For instance, use of drugs for selection would likely also impede growth of the host plant. Rhizophagus irregularis (previously Glomus intraradices) has also been subjected to AtMT, using as a selection system the delivery of constructs that express a nuclear-localized GFP [217]. The method was inefficient, hindered by the natural levels of autofluoresence of the fungus, and transformation success could not be confirmed with other approaches.

\section{All that shines is not silver: problems and limitations with the AtMT technique}

The previous sections are highlights in which the use of AtMT has led to new and major advances in fungi. However, not all is perfect with the tool, and researchers should consider some of these limitations when designing forward genetic experiments, planning to make targeted gene replacements, or interpreting data from strains generated with AtMT.

Given that generating hundreds or thousands of mutants is a prerequisite for functional genomic studies, several adaptations to the $A t \mathrm{MT}$ pipeline have been made to overcome significant experimental limitations and ensure this technique is sufficiently high-throughput. In some instances, technical challenges cannot be obviated. For example, while 96-well high throughput protocols exist for lithium acetate or protoplast-PEG mediated transformation of model yeasts [218], similar experiments in 96-well format are not possible using AtMT. This is likely due to the technical challenges of miniaturising Agrobacterium cultures, which must be sufficiently aerated to reach an optimised growth phase prior to transformation. Nevertheless, much progress 
has been made in reducing the burden of experimentally intensive cloning for $A t \mathrm{MT}$, which relies on generation of Agrobacterium compatible plasmids. Such cloning is more challenging when compared to lithium acetate or PEG mediated transformation, where linear DNA cassettes can be assembled by simple PCR steps [219]. Investigators have generated Agrobacterium plasmids that are compatible with Gateway ${ }^{\circledR}$ cloning technology from Invitrogen, e.g. enabling ultra-high throughput generation of Z. tritici over-expression strains [220]. Elsewhere, Agrobacterium compatible vector construction using yeast recombination in S. cerevisiae [14-16], or Golden Gate assembly [18], provide comparable improvements in high throughput vector construction. These studies highlight how some important technical challenges have been addressed, and their recent utilization demonstrate AtMT is applicable for high throughput functional genomic analyses of fungi [220]. More generally, they highlight that AtMT is a robust technique that will continue to be essential for analysis of fungi in the "big data" era of fungal functional genomics, as long as AtMT is used taking into consideration both the advantages and the limitations of the technique. Four points to consider are as follows.

First, an ideal insertional mutagenesis protocol should provide the ability to "hit" any and every gene, but T-DNA insertions have non-random integration patterns into fungal genomes. A single gene example of this bias is illustrated by the isolation of T-DNA insertional mutants into the $L A C 1$ gene encoding laccase for melanin biosynthesis in $C$. neoformans. Five insertions have been isolated within a $1 \mathrm{~kb}$ promoter region and none in the $2.8 \mathrm{~kb}$ coding region $[157,159,160]$ (Fig. 4a). This single gene example is consistent with insertional bias from the analysis of collectively thousands of T-DNA insertion strains in the plant pathogenic ascomycetes (see examples given above, and illustrated from P. oryzae in Fig. 4b). This is perhaps the biggest limitation to the use of AtMT as a tool for creating a library of mutants with insertions in every gene.

Despite this limitation, the skew to insert the T-DNA outside of genes has been recently converted into an advantage for the identification of essential genes [16]. The regulatory sequences for the C. neoformans GAL7 gene were cloned adjacent to the right border, and transformed into the basidiomycete C. neoformans. Transformation and selection was conducted on media containing galactose to ensure any gene near that insertion would be expressed, and then strains tested for growth on glucose, which represses GAL7 expression. Approximately $1 \%$ of transformants did not grow on glucose media. Analysis of the positions of the T-DNA insertions in the
C. neoformans genome revealed they were in genes with essential functions in ascomycete species.

Second, in ideal cases the T-DNA inserts perfectly from right to left border, the subsequent mutant (or set of mutants) with an interesting phenotype is isolated, followed by rapid identification of the gene of interest. Identification of the deleted or disrupted gene might be achieved by TAIL-PCR, inverse PCR, or some other method. However, this gene identification step can become a bottleneck or even end point for several reasons. The T-DNA may insert in ways which make subsequent mapping challenging, for example following signficiant cassette truncation, insertion of additional plasmid DNA beyond the border sequences, or with multiple copies either inserted in tandem or dispersed throughout the genome. The insertion events can be associated with deletions and chromosomal rearrangements of the genome. The tendency for insertions to fall within intergenic regions can cause issues establishing which of the two genes may be affected by the T-DNA, and sometimes qPCR of both genes can help identifying which one is affected by the insertion. In many cases the assumption is that the insertion will reduce expression of the adjacent genes. However, there are also examples such as from $L$. maculans in which the insertion event causes an increase in gene expression of adjacent genes [95].

Third, AtMT may not be able to provide valuable insighs compared to other transformation methods in some species. For a number of fungi, AtMT did not enhance our understanding of gene function in fungi. This includes the first fungus transformed using A. tumefaciens, S. cerevisiae [2]. This makes sense given the other transformation techniques available for $S$. cerevisiae, the ability to use chemical mutagenesis and then clone by complementation, construction and access to sets of strains with all the genes deleted, and other genomiclevel resources. Hence, with so many tools to isolate mutants and identify the affected gene, or screening whole genome deletion sets for phenotypes, there was little additional benefit of having AtMT as another tool. As mentioned above, a similar situation exists for the filamentous fungus model $N$. crassa: although one of the first filamentous species transformed with Agrobacterium [4] the method was not used since that time. A third example is Schizosaccharomyces pombe, a model used to uncover regulators of cell cycle control that was the topic of the 2001 Nobel Prize in Physiology or Medicine; indeed, this species and it seems no member of the Taphrinomycotina have been transformed with this method.

A fourth limitation with AtMT is that transformation with T-DNA will always be insertional, whereas in some fungi, such as $U$. maydis [221] or with the use of the 
AMA1 sequence in plasmids for Aspergillus spp. [222], plasmids that replicate autonomously are available. Such plasmids can be rescued back into $E$. coli, easing the way for cloning by complementation, or for deliberate loss by counter-selection.

\section{The future and further maximizing the impact of AtMT in fungi}

AtMT is a tool that is applicable to plant and fungal molecular biology, but the host side of the transformation is little understood. A set of 129 A. thaliana mutants has been identified that are resistant to transformation [223]. However, the fungi surpass all other eukaryotes in terms of the molecular tools and resources available for their study at the genome-wide scale and as such could be ideal hosts to define the eukaryotic side of the host cell-bacterial cell interaction. The process of T-DNA transfer and integration has been recently reviewed [7]. Using fungi as the host could provide insights into ways of improving efficiency of the method and the mechanisms by which the T-DNA is integrated. S. cerevisiae mutants have been used to identify those that have altered efficiency of transformation [224-229], and a discovery of the role of purine concentrations and biosynthesis was then also linked to transformation efficiency in plants [230]. Hence, testing other deletion sets, such as for $S$. pombe or the ongoing projects for N. crassa or C. neoformans, to find strains recalcitrant to transformation. The rationale for exploring the eukaryotic genes required for transformation in multiple species is because there are clear differences between fungi, e.g. gene replacement using AtMT is not possible in C. neoformans but it is in other basidiomycetes or in S. cerevisiae the influence of purine during transformation on efficiency is dependent on both genes for purine synthesis and the yeast strain [230]. This research direction could have wide impact, if that information could be transferred across to explain why some plant species are difficult to transform with the method. The other side of the transformation interaction is $A$. tumefaciens itself. There is evidence that different strains of $A$. tumefaciens behave differently. Few studies have investigated strains side-by-side for bias in insert preference or gene targeting efficiency.

AtMT can be a powerful teaching tool. "It is in human nature to value any novelty, however slight, in one's own possession" [231]. Those who have discovered a new mutant or mutant phenotype will appreciate the insight of Charles Darwin's comment, particularly for engaging students or others at many education levels with science. It is not known how many people have used AtMT as a teaching tool on the philosophy underlying molecular genetics, i.e. the phenotype of a mutant reflects the inverse of its function in the cell. In an undergraduate practical class setting, it is an effective method for demonstrating this principle, as well as exposing students to fundamental aspects of biology. The method has been taught at the Marine Biological Laboratory Molecular Mycology course (Woods Hole, MA, USA) since 2004 where students have performed large-scale mutant screens as part of research projects [166, 173, 232].

Several of the authors of this review have used AtMT as a teaching tool for undergraduates or even high school students, in cases resulting in the students contributing to research publications $[89,159,193,233]$. For implementing AtMT as a teaching tool, it is wise to select phenotype screens whereby multiple genes can control that particular phenotype to increase the chances of students isolating mutants.

It is essential to make any new method or resources available, such as through the deposition of plasmids or strains. One drawback of the use of $A$. tumefaciens is that some countries classify laboratory strains of $A$. tumefaciens as plant pathogens and have import restrictions due to this classification. An invaluable role has been and continues to be played by public repositories, such as the Fungal Genetics Stock Center in the USA. However, lack of funding for such organizations both threatens these and undermines decades of research and limits the potential to perform experiments into the future [234]. In addition to the physical resources, online databases of genomes, T-DNA insertions and phenotypes (Fig. 3) also require ongoing support to avoid the loss of this hardgained information.

At present, the identification of T-DNA junctions can still be a rate-limiting step. Sequencing a genome can be more cost effective than PCRs or other methods to identify junctions. Indeed, next generation sequencing has been applied for the identification of the mutated genes. In the case of L. maculans, there was difficulty in identifying junctions and four strains were sequenced separately to identify the T-DNA insertion sites [100]. Another approach was used for $C$. neoformans in which pools of DNA from mutants were sequenced simultaneously, and then the affected genes in the individual strains identified by specific PCRs [168, 232]. In future, incorporating signature tags, bar codes or using asymmetric restriction enzymes will make identification of flanking regions easier with the next-generation sequencing capabilities that are available.

In plants there have been many reports of using cotransformation to introduce multiple T-DNA cassettes at the same time (e.g. [235]); however, this is not a common approach in fungi [236]. Such an approach has the potential to allow AtMT delivery of separate partial selection 
cassettes, in a similar approach to that used very successfully in the bipartite or split-marker approach to enhancing targeted gene disruption in fungi [219]. Future implementation may further enhance gene targeting abilities in fungi [237, 238].

An exciting tool in biological research is the CRISPR/ Cas genome editing systems and likely, as AtMT did in the last 2 decades, this methodology could revolutionize fungal biology. As with AtMT in S. cerevisiae, it is likely that for the well-established fungi CRISPR/ Cas will be less ground breaking than for those species with challenges, especially species with low frequencies of targeted gene replacements. It is also worth pointing out that for many fungi AtMT will still be an instrumental tool to transform in the CRISPR/Cas constructs. Another feature of $A t \mathrm{MT}$ yet to be exploited in fungi is transient transformation. In plants this has been a routine method for introduction of constructs such as viral infectious clones [239], and given the difficulty currently faced with manipulation of mycoviruses, it is likely that such deployment will occur in the future. There is also interest in exploiting the transient transformation systems for other purposes like CRISPR/Cas that would circumvent the need to have this system integrated into the genome and the potential that causes for off-target mutations. In Ascomycetes this has been achieved by exploiting unstable autonomous vectors delivered by protoplast transformation [240, 241], whilst in $U$. maydis an unstable autonomous plasmid was successfully deployed into protoplasts to deliver an efficient CRISPR/ Cas system [242], but clearly there is also the possibility of exploiting the benefits of AtMT for such cases in the future, potentially by modification of some of the components required for integration of the T-DNA into the fungal genome.

\section{Concluding remarks}

In closing, nearly 20 years on we have a chance to answer Dunn-Coleman and Wang's question about AtMT, "a silver bullet for filamentous fungi?" This "silver bullet" conjures a mixture of concepts, ranging from the use of silver against werewolves, Paul Ehrlich's "magische Kugel”, or the lesser metal status of silver over gold. The perfect agent to comprehensively determine gene function in fungi, which ultimately provide these species with their remarkable capabilities, is likely elusive. AtMT has, however, achieved many milestones in defining the genetic basic behind numerous and diverse traits, and promises to continue to play an important role for our understanding of fungal biology.

\section{Authors' contributions}

All authors contributed to writing the manuscript. All authors read and approved the final manuscript.

\section{Author details}

${ }^{1}$ School of BioSciences, University of Melbourne, Melbourne, VIC 3010,

Australia. ${ }^{2}$ School of Biological Sciences, University of Bristol, Bristol, UK.

${ }^{3}$ Department of Applied and Molecular Microbiology, Technische Universität Berlin, Berlin, Germany. ${ }^{4}$ Department of Molecular Genetics and Microbiology, Duke University Medical Center, Durham, USA. ${ }^{5}$ College of Life and Applied

Sciences, Yeungnam University, Gyeongsan, South Korea.

\section{Acknowledgements}

We thank Barbara Howlett for comments and edits on the manuscript.

\section{Competing interests}

The authors declare that they have no competing interests.

Availability of data and materials

Not applicable.

Consent for publication

Not applicable.

Ethics approval and consent to participate

Not applicable.

\section{Funding}

Research that has used AtMT by the authors has been supported by the following organizations: United States National Institutes of Health (Al094364 Al and GI), Australian Research Council (FT130100146 Al), Procter and Gamble (Al and GI), Australian Grains Research and Development Corporation (UM00050 Al and (EE), Technische Universität Berlin Postdoctoral Research Funding (TCC), and the Biotechnology and Biological Sciences Research Council, UK (D19266 AMB).

\section{Publisher's Note}

Springer Nature remains neutral with regard to jurisdictional claims in published maps and institutional affiliations.

Received: 3 July 2017 Accepted: 18 September 2017

Published online: 26 September 2017

References

1. Dunn-Coleman N, Wang H. Agrobacterium T-DNA: a silver bullet for filamentous fungi? Nat Biotechnol. 1998;16:817-8.

2. Bundock P, den Dulk-Ras A, Beijersbergen A, Hooykaas PJJ. Trans-kingdom T-DNA transfer from Agrobacterium tumefaciens to Saccharomyces cerevisiae. EMBO J. 1995;14:3206-14.

3. Piers KL, Heath JD, Liang X, Stephens KM, Nester EW. Agrobacterium tumefaciens-mediated transformation of yeast. Proc Natl Acad Sci USA. 1996;93:1613-8.

4. de Groot MJA, Bundock P, Hooykaas PJJ, Beijersbergen AGM. Agrobacterium tumefaciens-mediated transformation of filamentous fungi. Nat Biotechnol. 1998;16:839-42.

5. Michielse CB, Hooykaas PJJ, van den Hondel CAMJJ, Ram AFJ. Agrobacterium-mediated transformation as a tool for functional genomics in fungi. Curr Genet. 2005;48:1-17.

6. Frandsen RJN. A guide to binary vectors and strategies for targeted genome modification in fungi using Agrobacterium tumefaciens-mediated transformation. J Microbiol Methods. 2011;87:247-62.

7. Bourras S, Rouxel T, Meyer M. Agrobacterium tumefaciens gene transfer: how a plant pathogen hacks the nuclei of plant and nonplant organisms. Phytopathology. 2015;105:1288-301.

8. Lacroix B, Citovsky V. The roles of bacterial and host plant factors in Agrobacterium-mediated genetic transformation. Int J Dev Biol. 2013;57:467-81.

9. Kyndt T, Quispe D, Zhai H, Jarret R, Ghislain M, Liu Q, Gheysen G, Kreuze JF. The genome of cultivated sweet potato contains Agrobacterium T-DNAs with expressed genes: an example of a naturally transgenic food crop. Proc Natl Acad Sci USA. 2015;112:5844-9. 
10. Young JM, Kuykendall LD, Martínez-Romero E, Kerr A, Sawada HA, et al. A revision of Rhizobium Frank 1889, with an emended description of the genus, and the inclusion of all species of Agrobacterium Conn 1942 and Allorhizobium undicola de Lajudie et al. 1998 as new combinations: Rhizobium radiobacter, $R$. rhizogenes, $R$. rubi, $R$. undicola and $R$. vitis. Int J Syst Evol Microbiol. 2001;51:89-103.

11. Lacroix B, Citovsky V. Transfer of DNA from bacteria to eukaryotes. mBio. 2016;7:e00863-00816.

12. Knight CJ, Bailey AM, Foster GD. Investigating Agrobacterium-mediated transformation of Verticillium albo-atrum on plant surfaces. PLOS ONE. 2010:5:e13684.

13. Machida M, Asai K, Sano M, Tanaka T, Kumagai T, Terai G, Kusumoto K, Arima T, Akita O, Kashiwagi Y, et al. Genome sequencing and analysis of Aspergillus oryzae. Nature. 2005;438:1157-61.

14. Kilaru S, Steinberg G. Yeast recombination-based cloning as an efficient way of constructing vectors for Zymoseptoria tritici. Fungal Genet Biol. 2015;79:76-83.

15. Lu J, Cao H, Zhang L, Huang P, Lin F. Systematic analysis of $Z_{2} \mathrm{Cys}_{6}$ transcription factors required for development and pathogenicity by high-throughput gene knockout in the rice blast fungus. PLoS Pathog. 2014;10:e1004432.

16. Ianiri G, Boyce KJ, Idnurm A. Isolation of conditional mutations in genes essential for viability of Cryptococcus neoformans. Curr Genet. 2017;63:519-30.

17. Sidhu YS, Chaudhari YK, Usher J, Cairns TC, Csukai M, Haynes K. A suite of Gateway ${ }^{\circledR}$ compatible ternary expression vectors for functional analysis in Zymoseptoria tritici. Fungal Genet Biol. 2015;79:180-5.

18. Engler C, Youles M, Gruetzner R, Ehnert T-M, Werner S, Jones JDG, Patron NJ, Marillonnet S. A Golden Gate modular cloning toolbox for plants. ACS Synth Biol. 2014;3:839-43.

19. Takken FLW, van Wijk R, Michielse CB, Houterman PM, Ram AFJ, Cornelissen BJC. A one-step method to convert vectors into binary vectors suited for Agrobacterium-mediated transformation. Curr Genet. 2004; 45:242-8.

20. Ali S, Bakkeren G. Introduction of large DNA inserts into the barley pathogenic fungus, Ustilago hordei, via recombined binary BAC vectors and Agrobacterium-mediated transformation. Curr Genet. 2011;57:63-73.

21. van den Berg MA, Maruthachalam K. Genetic transformation systems in fungi, vol. I \& II. Switzerland: Springer; 2015.

22. Ito H, Fukuda Y, Murata K, Kimura A. Transformation of intact yeast cells treated with alkali cations. J Bacteriol. 1983;153:163-8.

23. Kunik T, Tzfira T, Kapulnik Y, Gafni Y, Dingwall C, Citovsky V. Genetic transformation of HeLa cells by Agrobacterium. Proc Natl Acad Sci USA. 2001;98:1871-6.

24. Vijn I, Govers F. Agrobacterium tumefaciens mediated transformation of the oomycete plant pathogen Phytophthora infestans. Mol Plant Pathol. 2003:4:459-68.

25. Khrunyk Y, Münch K, Schipper K, Lupas AN, Kahmann R. The use of FLP-mediated recombination for the functional analysis of an effector gene family in the biotrophic smut fungus Ustilago maydis. New Phytol. 2010;187:957-68.

26. Grigoriev IV, Nikitin R, Haridas S, Kuo A, Ohm R, Otillar R, Riley R, Salamov A, Zhao X, Korzeniewski F, et al. MycoCosm portal: gearing up for 1000 fungal genomes. Nucleic Acids Res. 2014;42:D699-704.

27. Gamboa-Meléndez H, Judelson HS. Development of a bipartite ecdysone-responsive gene switch for the oomycete Phytophthora infestans and its use to manipulate transcription during axenic culture and plant infection. Mol Plant Pathol. 2015;16:83-91.

28. Arazoe T, Miyoshi K, Yamato T, Ogawa T, Ohsato S, Arie T, Kuwata S. Tailor-made CRISPR/Cas system for highly efficient targeted gene replacement in the rice blast fungus. Biotechnol Bioeng. 2015;1 12:2543-9.

29. Cairns TC, Studholme DJ, Talbot NJ, Haynes K. New and improved techniques for the study of pathogenic fungi. Trends Microbiol. 2016;24:35-50.

30. Dean R, Van Kan JAL, Pretorius ZA, Hammond-Kosack KE, Di Pietro A, Spanu PD, Rudd JJ, Dickman M, Kahmann R, Ellis J, et al. The top 10 fungal pathogens in molecular plant pathology. Mol Plant Pathol. 2012;13:414-30.

31. Klaubauf S, Tharreau D, Fournier E, Groenewald JZ, Crous PW, de Vries RP, Lebrun M-H. Resolving the polyphyletic nature of Pyricularia (Pyriculariaceae). Stud Mycol. 2014;79:85-120.
32. Zeigler RS, Leong SA, Teng PS. Rice blast disease. Wallingford: C.A.B. International, International Rice Research Institute; 1994.

33. Talbot NJ. On the trail of a cereal killer: exploring the biology of Magnaporthe grisea. Annu Rev Microbiol. 2003;57:177-202.

34. Martin-Urdiroz M, Oses-Ruiz M, Ryder LS, Talbot NJ. Investigating the biology of plant infection by the rice blast fungus Magnaporthe oryzae. Fungal Genet Biol. 2016;90:61-8.

35. Dean RA, Talbot NJ, Ebbole DJ, Farman ML, Mitchell TK, Orbach MJ, Thon M, Kulkarni R, Xu J-R, Pan H, et al. The genome sequence of the rice blast fungus Magnaporthe grisea. Nature. 2005;434:980-6.

36. Sweigard JA, Carroll AM, Farrall L, Chumley FG, Valent B. Magnaporthe grisea pathogenicity genes obtained through insertional mutagenesis. Mol Plant Microbe Interact. 1998;11:404-12.

37. Hamer L, Adachi K, Montenegro-Chamorro MV, Tanzer MM, Mahanty SK, Lo C, Tarpey RW, Skalchunes AR, Heiniger RW, Frank SA, et al. Gene discovery and gene function assignment in filamentous fungi. Proc Natl Acad Sci USA. 2001;98:5110-5.

38. Jeon J, Park S-Y, Chi M-H, Choi J, Park J, Rho H-S, Kim S, Goh J, Yoo S, Choi J, et al. Genome-wide functional analysis of pathogenicity genes in the rice blast fungus. Nat Genet. 2007;39:561-5.

39. Betts MF, Tucker SL, Galadima N, Meng Y, Patel G, Li L, Donofrio N, Floyd A, Nolin S, Brown D, et al. Development of a high throughput transformation system for insertional mutagenesis in Magnaporthe oryzae. Fungal Genet Biol. 2007:44:1035-49.

40. Choi J, Park J, Jeon J, Chi M-H, Goh J, Yoo S-Y, Park J, Jung K, Kim H, Park $\mathrm{S}$-Y, et al. Genome-wide analysis of T-DNA integration into the chromosomes of Magnaporthe oryzae. Mol Microbiol. 2007;66:371-82.

41. Li G, Zhou Z, Liu G, Zheng F, He C. Characterization of T-DNA insertion patterns in the genome of rice blast fungus Magnaporthe oryzae. Curr Genet. 2007;51:233-43.

42. Meng Y, Patel G, Heist M, Betts MF, Tucker SL, Galadima N, Donofrio NM, Brown D, Mitchell TK, Li L, et al. A systematic analysis of T-DNA insertion events in Magnaporthe oryzae. Fungal Genet Biol. 2007:44:1050-64

43. Foster AJ, Jenkinson JM, Talbot NJ. Trehalose synthesis and metabolism are required at different stages of plant infection by Magnaporthe grisea. EMBO J. 2003;22:225-35.

44. Chi MH, Park SY, Kim S, Lee YH. A novel pathogenicity gene is required in the rice blast fungus to suppress the basal defenses of the host. PLoS Pathog. 2009;5:e1000401.

45. Fones H, Gurr S. The impact of Septoria tritici Blotch disease on wheat: An EU perspective. Fungal Genet Biol. 2015;79:3-7.

46. Torriani SFF, Melichar JPE, Mills C, Pain N, Sierotzki H, Courbot M. Zymoseptoria tritici: a major threat to wheat production, integrated approaches to control. Fungal Genet Biol. 2015;79:8-12.

47. Payne AC, Grosjean-Cournoyer M-C, Hollomon DW. Transformation of the phytopathogen Mycosphaerella graminicola to carbendazim and hygromycin B resistance. Curr Genet. 1998;34:100-4.

48. Szewczyk E, Nayak T, Oakley CE, Edgerton H, Xiong Y, Taheri-Talesh N, Osmani SA, Oakley BR. Fusion PCR and gene targeting in Aspergillus nidulans. Nat Protoc. 2006;1:3111-20.

49. Adachi K, Nelson GH, Peoples KA, Frank SA, Montenegro-Chamorro MV, DeZwaan TM, Ramamurthy L, Shuster JR, Hamer L, Tanzer MM. Efficient gene identification and targeted gene disruption in the wheat blotch fungus Mycosphaerella graminicola using TAGKO. Curr Genet. 2002;42:123-7.

50. Skinner W, Bailey A, Renwick A, Keon J, Gurr S, Hargreaves J. A single amino-acid substitution in the iron-sulphur protein subunit of succinate dehydrogenase determines resistance to carboxin in MycosphaereIla graminicola. Curr Genet. 1998;34:393-8.

51. Talbot NJ. Taming a wild beast: developing molecular tools and new methods to understand the biology of Zymoseptoria tritici. Fungal Genet Biol. 2015;79:193-5.

52. Motteram J, Lovegrove A, Pirie E, Marsh J, Devonshire J, van de Meene A, Hammond-Kosack K, Rudd JJ. Aberrant protein N-glycosylation impacts upon infection-related growth transitions of the haploid plant-pathogenic fungus Mycosphaerella graminicola. Mol Microbiol. 2011;81:415-33.

53. Cousin A, Mehrabi R, Guilleroux M, Dufresne M, van der Lee T, Waalwijk C, Langin T, Kema GHJ. The MAP kinase-encoding gene MgFus3 of the non-appressorium phytopathogen Mycosphaerella graminicola 
is required for penetration and in vitro pycnidia formation. Mol Plant Pathol. 2006;7:269-78.

54. Mehrabi R, van der Lee T, Waalwijk C, Kema GHJ. MgSIt2, a cellular integrity MAP kinase gene of the fungal wheat pathogen MycosphaereIla graminicola, is dispensable for penetration but essential for invasive growth. Mol Plant Microbe Interact. 2006;19:389-98.

55. Michielse CB, Rep M. Pathogen profile update: Fusarium oxysporum. Mol Plant Pathol. 2009;10:311-24.

56. O'Donnell K, Rooney AP, Proctor RH, Brown DW, McCormick SP, Ward TJ, Frandsen RJN, Lysøe E, Rehner SA, Aoki T, et al. Phylogenetic analyses of $R P B 1$ and RPB2 support a middle Cretaceous origin for a clade comprising all agriculturally and medically important fusaria. Fungal Genet Biol. 2013:52:20-31.

57. Ma L-J, van der Does HC, Borkovich KA, Coleman JJ, Daboussi M-J, Di Pietro A, Dufresne M, Freitag M, Grabherr M, Henrissat B, et al. Comparative genomics reveals mobile pathogenicity chromosomes in Fusarium. Nature. 2010;464:367-73.

58. Ortoneda M, Guarro J, Madrid MP, Caracuel Z, Roncero MIG, Mayayo E, Di Pietro A. Fusarium oxysporum as a multihost model for the genetic dissection of fungal virulence in plants and mammals. Infect Immun. 2004;72:1760-6.

59. Kistler HC, Benny UK. Genetic transformation of the fungal plant wilt pathogen, Fusarium oxysporum. Curr Genet. 1988;13:145-9.

60. Diolez A, Langin T, Gerlinger C, Brygoo Y, Daboussi M-J. The nia gene of Fusarium oxysporum: isolation, sequence and development of a homologous transformation system. Gene. 1993;131:61-7.

61. Proctor RH, Hohn TM, McCormick SP. Reduced virulence of Gibberella zeae caused by disruption of a trichothecene toxin biosynthetic gene. Mol Plant-Microbe Interact. 1995;8:593-601.

62. Mullins ED, Kang S. Transformation: a tool for studying fungal pathogens of plants. Cell Mol Life Sci. 2001;58:2043-52.

63. Covert SF, Kapoor P, Lee M-H, Briley A, Nairn CJ. Agrobacterium tumefaciens-mediated transformation of Fusarium circinatum. Mycol Res. 2001;105:259-64.

64. Mullins ED, Chen X, Romaine P, Raina R, Geiser DM, Kang S. Agrobacterium-mediated transformation of Fusarium oxysporum: an efficient tool for insertional mutagenesis and gene transfer. Phytopathology. 2001;91:173-80

65. Malz S, Grell MN, Thrane C, Maier FJ, Rosager P, Felk A, Albertsen KS, Salomon S, Bohn L, Schäfer W, et al. Identification of a gene cluster responsible for the biosynthesis of aurofusarin in the Fusarium graminearum species complex. Fungal Genet Biol. 2005;42:420-33.

66. Visentin I, Montis V, Döll K, Alabouvette C, Tamietti G, Karlovsky P, Cardinale F. Transcription of genes in the biosynthetic pathway for fumonisin mycotoxins is epigenetically and differentially regulated in the fungal maize pathogen Fusarium verticillioides. Eukaryot Cell. 2012;11:252-9.

67. Pudake RN, Swaminathan S, Sahu BB, Leandro LF, Bhattacharyya MK. Investigation of the Fusarium virguliforme futox 1 mutants revealed that the FvTox1 toxin is involved in foliar sudden death syndrome development in soybean. Curr Genet. 2013;59:107-17.

68. Sørensen LQ, Lysøe E, Larsen JE, Khorsand-Jamal P, Nielsen KF, Frandsen RJN. Genetic transformation of Fusarium avenaceum by Agrobacterium tumefaciens mediated transformation and the development of a USERBrick vector construction system. BMC Mol Biol. 2014;15:15.

69. Frandsen RJN, Frandsen M, Giese H. Targeted gene replacement in fungal pathogens via Agrobacterium tumefaciens-mediated transformation. Methods Mol Biol. 2012;835:17-45.

70. Urban M, King R, Hassani-Pak K, Hammond-Kosack KE. Whole-genome analysis of Fusarium graminearum insertional mutants identifies virulence associated genes and unmasks untagged chromosomal deletions. BMC Genom. 2015;16:261

71. Namiki F, Matsunaga M, Okuda M, Inoue I, Nishi K, Fujita Y, Tsuge T. Mutation of an arginine biosynthesis gene causes reduced pathogenicity in Fusarium oxysporum f. sp. melonis. Mol Plant-Microbe Interact. 2001;14:580-4.

72. Morita K, Kimura S, Saito M, Shinoyama H, Usami T, Amemiya Y, Shishido M. Generation and characterization of reduced virulence Fusarium oxysporum f. sp. Iycopersici mutants through plasmid-vector insertion. Mycopathologia. 2005;160:67-73.

73. López-Berges MS, Di PA, Daboussi M-J, Wahab HA, Vasnier C, Roncero MIG, Dufresne M, Hera C. Identification of virulence genes in Fusarium oxysporum f. sp. Iycopersici by large-scale transposon tagging. Mol. Plant Pathol. 2009;10:95-107.

74. Dufresne M, van der Lee T, Ben M'Barek S, Xu X, Zhang X, Liu T, Waalwijk C, Zhang W, Kema GHJ, Daboussi M-J. Transposon-tagging identifies novel pathogenicity genes in Fusarium graminearum. Fungal Genet Biol. 2008;45:1552-61.

75. Michielse CB, van Wijk R, Reijnen L, Cornelissen BJC, Rep M. Insight into the molecular requirements for pathogenicity of Fusarium oxysporum f. sp. lycopersici through large-scale insertional mutagenesis. Genome Biol. 2009;10:R4.

76. Li M-H, Xie X-L, Lin X-F, Shi J-X, Ding Z-J, Ling J-F, Xi P-G, Zhou J-N, Leng $Y$, Zhong $S$, et al. Functional characterization of the gene FoOCH1 encoding a putative a-1,6-mannosyltransferase in Fusarium oxysporum f. sp. cubense. Fungal Genet Biol. 2014;65:1-13.

77. Münch S, Lingner U, Floss DS, Ludwig N, Sauer N, Deising HB. The hemibiotrophic lifestyle of Colletotrichum species. J Plant Physiol. 2008;165:41-51.

78. De Silva DD, Crous PW, Ades PK, Hyde KD, Taylor PWJ. Life styles of Colletotrichum species and implications for plant biosecurity. Fungal Biol Rev. 2017:31:155-68.

79. Amnuaykanjanasin A, Epstein L. A class V chitin synthase gene, chsA is essential for conidial and hyphal wall strength in the fungus Colletotrichum graminicola (Glomerella graminicola). Fungal Genet Biol. 2003;38:272-85.

80. Dufresne M, Bailey JA, Dron M, Langin T. Ilk1, a serine/threonine protein kinase-encoding gene, is involved in pathogenicity of Colletotrichum lindemuthianum on common bean. Mol Plant-Microbe Interact. 1998;11:99-108.

81. Gu Q, Chen M, Huang J, Wei YD, Hsiang T, Zheng L. Multifaceted roles of the Ras guanine-nucleotide exchange factor ChRgf in development, pathogenesis, and stress responses of Colletotrichum higginsianum. Phytopathology. 2017;107:433-43.

82. Korn M, Schmidpeter J, Dahl M, Müller S, Voll LM, Koch C. A genetic screen for pathogenicity genes in the hemibiotrophic fungus Colletotrichum higginsianum identifies the plasma membrane proton pump Pma2 required for host penetration. PLOS ONE. 2015:10:e0125960.

83. Liu L, Zhao D, Zheng L, Hsiang T, Wei Y, Fu Y, Huang J. Identification of virulence genes in the crucifer anthracnose fungus Colletotrichum higginsianum by insertional mutagenesis. Microb Pathog. 2013;64:6-17.

84. Huser A, Takahara H, Schmalenbach W, O'Connell R. Discovery of pathogenicity genes in the crucifer anthracnose fungus Colletotrichum higginsianum, using random insertional mutagenesis. Mol Plant-Microbe Interact. 2009;22:143-56.

85. Wu J, Ji Z, Wang N, Chi F, Xu C, Zhou Z, Zhang J. Identification of conidiogenesis-associated genes in Colletotrichum gloeosporioides by Agrobacterium tumefaciens-mediated transformation. Curr Microbiol. 2016;73:802-10.

86. Cai Z, Li G, Lin C, Shi T, Zhai L, Chen Y, Huang G. Identifying pathogenicity genes in the rubber tree anthracnose fungus Colletotrichum gloeosporioides through random insertional mutagenesis. Microbiol Res. 2013;168:340-50.

87. Schmidpeter J, Dahl M, Hofmann J, Koch C. ChMob2 binds to ChCbk1 and promotes virulence and conidiation of the fungal pathogen Colletotrichum higginsianum. BMC Microbiol. 2017;17:22.

88. Kodama S, Ishizuka J, Miyashita I, Ishii T, Nishiuchi T, Miyoshi H, Kubo Y. The morphogenesis-related NDR kinase pathway of Colletotrichum orbiculare is required for translating plant surface signals into infection-related morphogenesis and pathogenesis. PLoS Pathog. 2017;13:e1006189.

89. Walton FJ, Heitman J, Idnurm A. Conserved elements of the RAM signaling pathway establish cell polarity in the basidiomycete Cryptococcus neoformans in a divergent fashion from other fungi. Mol Biol Cell. 2006; 17:3768-80.

90. West JS, Kharbanda PD, Barbetti MJ, Fitt BDL. Epidemiology and management of Leptosphaeria maculans (phoma stem canker) on oilseed rape in Australia, Canada and Europe. Plant Pathol. 2001;50:10-27.

91. Farman ML, Oliver RP. The transformation of protoplasts of Leptosphaeria maculans to hygromycin B resistance. Curr Genet. 1988;13:327-30.

92. Idnurm A, Howlett BJ. Analysis of loss of pathogenicity mutants reveals that repeat-induced point mutations can occur in the Dothideomycete Leptosphaeria maculans. Fungal Genet Biol. 2003;39:31-7. 
93. Idnurm A, Taylor JL, Pedras MSC, Howlett BJ. Small scale functional genomics of the blackleg fungus, Leptosphaeria maculans: analysis of a $38 \mathrm{~kb}$ region. Australas Plant Pathol. 2003;32:511-9.

94. GardinerDM, HowlettBJ.Negative selection using thymidinekinase increases the efficiency of recovery of transformants with targeted genes in the filamentous fungus Leptosphaeria maculans. Curr Genet. 2004;45:249-55.

95. Elliott CE, Howlett BJ. Overexpression of a 3-ketoacyl-CoA thiolase in Leptosphaeria maculans causes reduced pathogenicity on Brassica napus. Mol Plant Microbe Interact. 2006;19:588-96.

96. Van de Wouw AP, Pettolino FA, Howlett BJ, Elliott CE. Mutations to LmIFRD affect cell wall integrity, development and pathogenicity of the ascomycete Leptosphaeria maculans. Fungal Genet Biol. 2009;46:695-706

97. Elliott CE, Fox EM, Jarvis RS, Howlett BJ. The cross-pathway control system regulates production of the secondary metabolite toxin, sirodesmin PL, in the ascomycete, Leptosphaeria maculans. BMC Microbiol. 2011;11:169.

98. Blaise F, Rémy E, Meyer M, Zhou L, Narcy J-P, Roux J, Balesdent M-H, Rouxel T. A critical assessment of Agrobacterium tumefaciens-mediated transformation as a tool for pathogenicity gene discovery in the phytopathogenic fungus Leptosphaeria maculans. Fungal Genet Biol. 2007:44:123-38.

99. Bourras S, Meyer M, Grandaubert J, Lapalu N, Fudal I, Linglin J, Ollivier B, Blaise $\mathrm{F}$, Balesdent $\mathrm{M}-\mathrm{H}$, Rouxel T. Incidence of genome structure, DNA asymmetry, and cell physiology on T-DNA integration in chromosomes of the phytopathogenic fungus Leptosphaeria maculans. G3. 2012;2:891-904

100. Chambers K, Lowe RGT, Howlett BJ, Zander M, Batley J, Van de Wouw AP, Elliott CE. Next-generation genome sequencing can be used to rapidly characterise sequences flanking T-DNA insertions in random insertional mutants of Leptosphaeria maculans. Fungal Biol Biotechnol. 2014;1:10.

101. Lowe RGT, Cassin A, Grandaubert J, Clark BL, Van de Wouw AP, Rouxel T, Howlett BJ. Genomes and transcriptomes of partners in plant-fungalinteractions between canola (Brassica napus) and two Leptosphaeria species. PLoS ONE. 2014;9:e103098.

102. Plissonneau C, Daverdin G, Ollivier B, Blaise F, Degrave A, Fudal I, Rouxel T, Balesdent M-H. A game of hide and seek between avirulence genes AvrLm4-7 and AvrLm3 in Leptosphaeria maculans. New Phytol. 2016:209:1613-24.

103. Assi MA, Sandid MS, Baddour LM, Roberts GD, Walker RC. Systemic histoplasmosis: a 15-year retrospective institutional review of 111 patients. Medicine (Baltimore). 2007:86:162-9.

104. Brown GD, Denning DW, Gow NAR, Levitz SM, Netea MG, White TC. Hidden killers: human fungal infections. Sci Transl Med. 2012:4:165rv113.

105. Magrini V, Goldman WE. Molecular mycology: a genetic toolbox for Histoplasma capsulatum. Trends Microbiol. 2001;9:541-6.

106. Woods JP, Heinecke EL, Goldman WE. Electrotransformation and expression of bacterial genes encoding hygromycin phosphotransferase and $\beta$-galactosidase in the pathogenic fungus Histoplasma capsulatum. Infect Immun. 1998;66:1697-707.

107. Sullivan TD, Rooney PJ, Klein BS. Agrobacterium tumefaciens integrates transfer DNA into single chromosomal sites of dimorphic fungi and yields homokaryotic progeny from multinucleate yeast. Eukaryot Cell. 2002;1:895-905.

108. Sil A, Andrianopoulos A. Thermally dimorphic human fungal pathogens-polyphyletic pathogens with a convergent pathogenicity trait. Cold Spring Harb Perspect Med. 2015;5:a019794.

109. Kemski MM, Stevens B, Rappleye CA. Spectrum of T-DNA integrations for insertional mutagenesis of Histoplasma capsulatum. Fungal Biol. 2013;117:41-51

110. Marion CL, Rappleye CA, Engle JT, Goldman WE. An a-(1,4)-amylase is essential for a-(1,3)-glucan production and virulence in Histoplasma capsulatum. Mol Microbiol. 2006;62:970-83.

111. Nguyen $V Q$, Sil A. Temperature-induced switch to the pathogenic yeast form of Histoplasma capsulatum requires Ryp1, a conserved transcriptional regulator. Proc Natl Acad Sci USA. 2008;105:4880-5.

112. Webster RH, Sil A. Conserved factors Ryp2 and Ryp3 control cell morphology and infectious spore formation in the fungal pathogen Histoplasma capsulatum. Proc Natl Acad Sci USA. 2008;105:14573-8.
113. Beyhan S, Gutierrez M, Voorhies M, Sil A. A temperature-responsive network links cell shape and virulence traits in a primary fungal pathogen. PLoS Biol. 2013;11:e1001614.

114. Hilty J, Smulian AG, Newman SL. The Histoplasma capsulatum vacuolar ATPase is required for iron homeostasis, intracellular replication in macrophages and virulence in a murine model of histoplasmosis. Mol Microbiol. 2008;70:127-39.

115. Edwards JA, Zemska O, Rappleye CA. Discovery of a role for Hsp82 in Histoplasma virulence through a quantitative screen for macrophage lethality. Infect Immun. 2011;79:3348-57.

116. Sebghati TS, Engle JT, Goldman WE. Intracellular parasitism by Histoplasma capsulatum: fungal virulence and calcium dependence. Science. 2000;290:1368-72.

117. Youseff BH, Dougherty JA, Rappleye CA. Reverse genetics through random mutagenesis in Histoplasma capsulatum. BMC Microbiol. 2009:9:236.

118. Fang W, Pei Y, Bidochka MJ. Transformation of Metarhizium anisopliae mediated by Agrobacterium tumefaciens. Can J Microbiol. 2006;52:623-6.

119. Leclerque A, Wan H, Abschütz A, Chen S, Mitina GV, Zimmermann G, Schairer HU. Agrobacterium-mediated insertional mutagenesis (AIM) of the entomopathogenic fungus Beauveria bassiana. Curr Genet. 2004;45:111-9.

120. Zhang Y-J, Zhao J-J, Xie M, Peng D-L. Agrobacterium tumefaciens-mediated transformation in the entomopathogenic fungus Lecanicillium lecanii and development of benzimidazole fungicide resistant strains. J Microbiol Methods. 2014:105:168-73.

121. Fan Y, Zhang S, Kruer N, Keyhani NO. High-throughput insertion mutagenesis and functional screening in the entomopathogenic fungus Beauveria bassiana. J Invertebr Pathol. 2011;106:274-9.

122. Moon Y-S, Donzelli BGG, Krasnoff SB, McLane H, Griggs MH, Cooke P, Vandenberg JD, Gibson DM, Churchill ACL. Agrobacterium-mediated disruption of a nonribosomal peptide synthetase gene in the invertebrate pathogen Metarhizium anisopliae reveals a peptide spore factor. Appl Environ Microbiol. 2008;74:4366-80.

123. Xu C, Zhang X, Qian Y, Chen X, Liu R, Zeng G, Zhao H, Fang W. A highthroughput gene disruption methodology for the entomopathogenic fungus Metarhizium robertsii. PLoS ONE. 2014;9:e107657.

124. Li M, Gong X, Zheng J, Jiang D, Fu Y, Hou M. Transformation of Coniothyrium minitans, a parasite of Sclerotinia sclerotiorum, with Agrobacterium tumefaciens. FEMS Microbiol Lett. 2005;243:323-9.

125. Amey RC, Mills PR, Bailey A, Foster GD. Investigating the role of a Verticillium fungicola $\beta$-1,6-glucanase during infection of Agaricus bisporus using targeted gene disruption. Fungal Genet Biol. 2003;39:264-75.

126. Collopy PD, Amey RC, Sergeant MJ, Challen MP, Mills PR, Foster GD, Bailey AM. The pmk1-like mitogen-activated protein kinase from Lecanicillium (Verticillium) fungicola is not required for virulence on Agaricus bisporus. Microbiology. 2010;156:1439-47.

127. Chen X, Stone M, Schlagnhaufer C, Romaine CP. A fruiting body tissue method for efficient Agrobacterium-mediated transformation of Agaricus bisporus. Appl Environ Microbiol. 2000;66:4510-3.

128. Baumgartner K, Fujiyoshi P, Foster GD, Bailey AM. Agrobacterium tumefaciens-mediated transformation for investigation of somatic recombination in the fungal pathogen Armillaria mellea. Appl Environ Microbiol. 2010;76:7990-6.

129. Ford KL, Baumgartner K, Henricot B, Bailey AM, Foster GD. A reliable in vitro fruiting system for Armillaria mellea for evaluation of Agrobacterium tumefaciens transformation vectors. Fungal Biol. 2015;119:859-69.

130. Burns C, Gregory KE, Kirby M, Cheung MK, Riquelme M, Elliott TJ, ChalIen MP, Bailey A, Foster GD. Efficient GFP expression in the mushrooms Agaricus bisporus and Coprinus cinereus requires introns. Fungal Genet Biol. 2005;42:191-9.

131. Kilaru S, Collins CM, Hartley AJ, Burns C, Foster GD, Bailey AM. Investigating dominant selection markers for Coprinopsis cinerea: a carboxin resistance system and re-evaluation of hygromycin and phleomycin resistance vectors. Curr Genet. 2009;55:543-50.

132. Burns C, Leach KM, Elliott TJ, Challen MP, Foster GD, Bailey A. Evaluation of Agrobacterium-mediated transformation of Agaricus bisporus using a range of promoters linked to hygromycin resistance. Mol Biotechnol. 2006:32:129-38. 
133. Zhang JJ, Shi L, Chen H, Sun YQ, Zhao MW, Ren A, Chen MJ, Wang $H$, Feng ZY. An efficient Agrobacterium-mediated transformation method for the edible mushroom Hypsizygus marmoreus. Microbiol Res. 2014;169:741-8.

134. Ford KL, Baumgartner K, Henricot B, Bailey AM, Foster GD. A native promoter and inclusion of an intron is necessary for efficient expression of GFP or mRFP in Armillaria mellea. Sci Rep. 2016:6:29226.

135. Hatoh K, Izumitsu K, Morita A, Shimizu K, Ohta A, Kawai M, Yamanaka T, Neda H, Ota Y, Tanaka C. Transformation of the mushroom species Hypsizigus marmoreus, Flammulina velutipes, and Grifola frondosa by an Agrobacterium-mediated method using a universal transformation plasmid. Mycoscience. 2013;54:8-12.

136. Janbon G, Ormerod KL, Paulet D, Byrnes EJ 3rd, Yadav V, Chatterjee G, Mullapudi N, Hon C-C, Billmyre RB, Brunel F, et al. Analysis of the genome and transcriptome of Cryptococcus neoformans var. grubii reveals complex RNA expression and microevolution leading to virulence attenuation. PLoS Genet. 2014;10:e1004261.

137. Stephan BI, Alvarez Crespo MC, Kemppainen MJ, Pardo AG. Agrobac terium-mediated insertional mutagenesis in the mycorrhizal fungus Laccaria bicolor. Curr Genet. 2017;63:215-27.

138. Wang J, Guo L, Zhang K, Wu Q, Lin J. Highly efficient Agrobacteriummediated transformation of Volvariella volvacea. Bioresour Technol. 2008;99:8524-7

139. Xu J-W, Xu Y-N, Zhong J-J. Enhancement of ganoderic acid accumulation by overexpression of an N-terminally truncated 3-hydroxy3-methylglutaryl coenzyme A reductase gene in the basidiomycete Ganoderma lucidum. Appl Environ Microbiol. 2012;78:7968-76.

140. Godio RP, Fouces R, Martín JF. A squalene epoxidase is involved in biosynthesis of both the antitumor compound clavaric acid and sterols in the basidiomycete H. sublateritium. Chem Biol. 2007;14:1334-46.

141. Lin Y-L, Lee Y-R, Tsao N-W, Wang S-Y, Shaw J-F, Chu F-H. Characterization of the 2,3-oxidosqualene cyclase gene from Antrodia cinnamomea and enhancement of cytotoxic triterpenoid compound production. J Nat Prod. 2015;78:1556-62.

142. Kemppainen MJ, Pardo AG. Gene knockdown by inpRNA-triggering in the ectomycorrhizal basidiomycete fungus Laccaria bicolor. Bioeng Bugs. 2010;1:354-8.

143. Kemppainen MJ, Pardo AG. pHg/pSILBAgamma vector system for efficient gene silencing in homobasidiomycetes: optimization of ihpRNA — triggering in the mycorrhizal fungus Laccaria bicolor. Microb Biotechnol. 2010;3:178-200.

144. Costa ASMB, Thomas DJI, Eastwood D, Cutler SB, Bailey AM, Foster GD, Mills PR, Challen MP. Quantifiable downregulation of endogenous genes in Agaricus bisporus mediated by expression of RNA hairpins. J Microbiol Biotechnol. 2009;19:271-6.

145. Heneghan MN, Burns C, Costa AMSB, Burton KS, Challen MP, Bailey AM, Foster GD. Functional analysis of Agaricus bisporus serine proteinase 1 reveals roles in utilization of humic rich substrates and adaptation to the leaf-litter ecological niche. Environ Microbiol. 2016;18:4687-96.

146. Nakazawa T, Ando Y, Kitaaki K, Nakahori K, Kamada T. Efficient gene targeting in $\triangle C c . k u 70$ or $\Delta C$ c.lig4 mutants of the agaricomycete Coprinopsis cinerea. Fungal Genet Biol. 2011;48:939-46.

147. Waltz E. Gene-edited CRISPR mushroom escapes US regulation. Nature. 2016;532:293

148. Hagen F, Khayhan K, Theelen B, Kolecka A, Polacheck I, Sionov E, Falk R, Parnmen S, Lumbsch HT, Boekhout T. Recognition of seven species in the Cryptococcus gattii/Cryptococcus neoformans species complex. Fungal Genet Biol. 2015;78:16-48.

149. Heitman J, Kozel TR, Kwon-Chung KJ, Perfect JR, Casadevall A, editors. Cryptococcus: from human pathogen to model yeast. Washington: American Society for Microbiology Press; 2011.

150. Idnurm A, Bahn Y-S, Nielsen K, Lin X, Fraser JA, Heitman J. Deciphering the model pathogenic fungus Cryptococcus neoformans. Nat Rev Microbiol. 2005:3:753-64.

151. Rajasingham R, Smith RM, Park BJ, Jarvis JN, Govender NP, Chiller TM, Denning DW, Loyse A, Boulware DR. Global burden of disease of HIVassociated cryptococcal meningitis: an updated analysis. Lancet Infect Dis. 2017;17:873-81.

152. Zhang N, Park Y-D, Williamson PR. New technology and resources for cryptococcal research. Fungal Genet Biol. 2015;78:99-107.
153. Edman JC, Kwon-Chung KJ. Isolation of the URA5 gene from Cryptococcus neoformans var. neoformans and its use as a selective marker for transformation. Mol Cell Biol. 1990;10:4538-44.

154. Toffaletti DL, Rude TH, Johnston SA, Durack DT, Perfect JR. Gene transfer in Cryptococcus neoformans by use of biolistic delivery of DNA. J Bacteriol. 1993;175:1405-11.

155. Kraus PR, Nichols CB, Heitman J. Calcium and calcineurin-independent roles for calmodulin in Cryptococcus neoformans morphogenesis and high-temperature growth. Eukaryot Cell. 2005:4:1079-87.

156. Zhu X, Williamson PR. A CLC-type chloride channel gene is required for laccase activity and virulence in Cryptococcus neoformans. Mol Microbiol. 2003;50:1271-82.

157. Idnurm A, Reedy JL, Nussbaum JC, Heitman J. Cryptococcus neoformans virulence gene discovery through insertional mutagenesis. Eukaryot Cell. 2004;3:420-9.

158. McClelland CM, Chang YC, Kwon-Chung KJ. High frequency transformation of Cryptococcus neoformans and Cryptococcus gattii by Agrobacterium tumefaciens. Fungal Genet Biol. 2005:42:904-13.

159. Walton FJ, Idnurm A, Heitman J. Novel gene functions required for melanization of the human pathogen Cryptococcus neoformans. Mol Microbiol. 2005;57:1381-96.

160. Idnurm A, Walton FJ, Floyd A, Reedy JL, Heitman J. Identification of ENA1 as a virulence gene of the human pathogenic fungus Cryptococcus neoformans through signature-tagged insertional mutagenesis. Eukaryot Cell. 2009:8:315-26

161. Hu G, Caza M, Cadieux B, Chan V, Liu V, Kronstad J. Cryptococcus neoformans requires the ESCRT protein Vps23 for iron acquisition from heme, for capsule formation, and for virulence. Infect Immun. 2013:81:292-302

162. Idnurm A, Heitman J. Light controls growth and development via a conserved pathway in the fungal kingdom. PLoS Biol. 2005:3:615-26.

163. Yeh Y-L, Lin Y-S, Su B-J, Shen W-C. A screening for suppressor mutants reveals components involved in the blue light-inhibited sexual filamentation in Cryptococcus neoformans. Fungal Genet Biol. 2009;46:42-54.

164. Feretzaki M, Heitman J. Genetic circuits that govern bisexual and unisexual reproduction in Cryptococcus neoformans. PLoS Genet. 2013;9:e1003688.

165. Verma S, Idnurm A. Uve1 endonuclease is regulated by White collar to protect Cryptococcus neoformans from UV damage. PLoS Genet. 2013:9:e1003769.

166. Lin X, Jackson JC, Feretzaki M, Xue C, Heitman J. Transcription factors Mat2 and Znf2 operate cellular circuits orchestrating opposite- and same-sex mating in Cryptococcus neoformans. PLoS Genet. 2010;6:e1000953

167. Chacko N, Zhao Y, Yang E, Wang L, Cai JJ, Lin X. The IncRNA RZE controls cryptococcal morphological transition. PLoS Genet. 2015;11:e1005692.

168. Gyawali R, Zhao Y, Lin J, Fan Y, Xu X, Upadhyay S, Lin X. Pheromone independent unisexual development in Cryptococcus neoformans. PLoS Genet. 2017;13:e1006772.

169. Fu J, Mares C, Lizcano A, Liu Y, Wickes BL. Insertional mutagenesis combined with an inducible filamentation phenotype reveals a conserved STE50 homologue in Cryptococcus neoformans that is required for monokaryotic fruiting and sexual reproduction. Mol Microbiol. 2011;79:990-1007.

170. Ianiri G, Idnurm A. Essential gene discovery in the basidiomycete Cryptococcus neoformans for antifungal drug target prioritization. mBio. 2015:6:e02334-02314

171. Chun CD, Madhani HD. Ctr2 links copper homeostasis to polysaccharide capsule formation and phagocytosis inhibition in the human fungal pathogen Cryptococcus neoformans. PLoS ONE. 2010;5:e12503.

172. Chang YC, Lamichhane AK, Garraffo HM, Walter PJ, Leerkes M, KwonChung KJ. Molecular mechanisms of hypoxic responses via unique roles of Ras1, Cdc24 and Ptp3 in a human fungal pathogen Cryptococcus neoformans. PLoS Genet. 2014;10:e1004292.

173. Ost KS, O'Meara TR, Huda N, Esher SK, Alspaugh JA. The Cryptococcus neoformans alkaline response pathway: identification of a novel rim pathway activator. PLoS Genet. 2015;11:e1005159.

174. Aime MC, Matheny PB, Henk DA, Frieders EM, Nilsson RH, Piepenbring M, McLaughlin DJ, Szabo LJ, Begerow D, Sampaio JP, et al. An overview of the higher level classification of Pucciniomycotina based on 
combined analyses of nuclear large and small subunit rDNA sequences. Mycologia. 2006;98:896-905.

175. Webb CA, Szabo LJ, Bakkeren G, Garry C, Staples RC, Eversmeyer M, Fellers JP. Transient expression and insertional mutagenesis of Puccinia triticina using biolistics. Funct Integr Genomics. 2006;6:250-60.

176. Lawrence GJ, Dodds PN, Ellis JG. Transformation of the flax rust fungus, Melampsora lini: selection via silencing of an avirulence gene. Plant J. 2010;61:364-9.

177. Toh SS, Perlin MH. Resurgence of less-studied smut fungi as models of phytopathogenesis in the omics age. Phytopathology. 2016;106:1244-54.

178. Hood ME. Dimorphic mating-type chromosomes in the fungus Microbotryum violaceum. Genetics. 2002;160:457-61.

179. Bej AK, Perlin MH. A high efficiency transformation system for the basidiomycete Ustilago violacea employing hygromycin resistance and lithium-acetate treatment. Gene. 1989;80:171-6.

180. Perlin MH, Bej AK, Will OH 3rd, Jacob RJ. Introduction and maintenance of prokaryotic DNA in Ustilago violacea. J Ind Microbiol. 1990;5:355-63.

181. Toh SS, Treves DS, Barati MT, Perlin MH. Reliable transformation system for Microbotryum lychnidis-dioicae informed by genome and transcriptome project. Arch Microbiol. 2016;198:813-25.

182. Perlin MH, Amselem J, Fontanillas E, Toh SS, Chen Z, Goldberg J, Duplessis S, Henrissat B, Young S, Zeng Q, et al. Sex and parasites: genomic and transcriptomic analysis of Microbotryum lychnidis-dioicae, the biotrophic and plant-castrating anther smut fungus. BMC Genom. 2015;16:461.

183. Wang Q-M, Yurkov AM, Göker M, Lumbsch HT, Leavitt SD, Groenewald M, Theelen B, Liu X-Z, Boekhout T, Bai F-Y. Phylogenetic classification of yeasts and related taxa within Pucciniomycotina. Stud Mycol. 2015;81:149-89.

184. Johnson EA. Biotechnology of non-Saccharomyces yeasts-the basidiomycetes. Appl Microbiol Biotechnol. 2013;97:7563-77.

185. Tully M, Gilbert HJ. Transformation of Rhodosporidium toruloides. Gene. $1985 ; 36: 235-40$

186. Ianiri G, Wright SAI, Castoria R, Idnurm A. Development of resources for the analysis of gene function in Pucciniomycotina red yeasts. Fungal Genet Biol. 2011:48:685-95.

187. Abbott EP, laniri G, Castoria R, Idnurm A. Overcoming recalcitrant transformation and gene manipulation in Pucciniomycotina yeasts. Appl Microbiol Biotechnol. 2013:97:283-95.

188. Liu Y, Koh CMJ, Sun L, Hlaing MM, Du M, Peng N, Ji L. Characterization of glyceraldehyde-3-phosphate dehydrogenase gene RtGPD1 and development of genetic transformation method by dominant selection in oleaginous yeast Rhodosporidium toruloides. Appl Microbiol Biotechnol. 2013:97:719-29.

189. Lin X, Wang Y, Zhang S, Zhu Z, Zhou YJ, Yang F, Sun W, Wang X, Zhao ZK Functional integration of multiple genes into the genome of the oleaginous yeast Rhodosporidium toruloides. FEMS Yeast Res. 2014;14:547-55.

190. Wang Y, Lin X, Zhang S, Sun W, Ma S, Zhao ZK. Cloning and evaluation of different constitutive promoters in the oleaginous yeast Rhodosporidium toruloides. Yeast. 2016;33:99-106.

191. laniri G, Idnurm A, Wright SAl, Durán-Patrón R, Mannina L, Ferracane R, Ritieni A, Castoria R. Searching for genes responsible for patulin degradation in a biocontrol yeast provides insight into the basis for resistance to this mycotoxin. Appl Environ Microbiol. 2013;79:3101-15.

192. Ianiri G, Idnurm A, Castoria R. Transcriptomic responses of the basidiomycete yeast Sporobolomyces sp. to the mycotoxin patulin. BMC Genom. 2016;17:210.

193. Ianiri G, Abhyankar R, Kihara A, Idnurm A. Phs 1 and the synthesis of very long chain fatty acids are required for ballistospore formation. PLoS ONE. 2014;9:e105147.

194. Zhang S, Skerker JM, Rutter CD, Maurer MJ, Arkin AP, Rao CV. Engineering Rhodosporidium toruloides for increased lipid production. Biotechnol Bioeng. 2016;113:1056-66.

195. Koh CMJ, Liu Y, Du Moehninsi M, Ji L. Molecular characterization of KU70 and KU80 homologues and exploitation of a KU70-deficient mutant for improving gene deletion frequency in Rhodosporidium toruloides. BMC Microbiol. 2014;14:50

196. Liu Y, Koh CMJ, Ngoh ST, Ji L. Engineering an efficient and tight D-amino acid-inducible gene expression system in Rhodosporidium/Rhodotorula species. Microb Cell Fact. 2015;14:170.
197. Liu Y, Yap SA, Kohn CMJ, Ji L. Developing a set of strong intronic promoters for robust metabolic engineering in oleaginous Rhodotorula (Rhodosporidium) yeast species. Microb Cell Fact. 2016;15:200.

198. Ji L, Jiang Z-D, Liu Y, Koh CM, Zhang L-H. A simplified and efficient method for transformation and gene tagging of Ustilago maydis using frozen cells. Fungal Genet Biol. 2010;47:279-87.

199. Marchand G, Fortier E, Neveu B, Bolduc S, Belzile F, Bélanger RR. Alternative methods for genetic transformation of Pseudozyma antarctica, a basidiomycetous yeast-like fungus. J Microbiol Methods. 2007;70:519-27.

200. Ianiri G, Averette AF, Kingsbury JM, Heitman J, Idnurm A. Gene function analysis in the ubiquitous human commensal and pathogen Malassezia genus. mBio. 2016;7:e01853-01816.

201. Celis AM, Vos AM, Triana S, Medina CA, Escobar N, Restrepo S, Wösten $H A B$, de Cock H. Highly efficient transformation system for Malassezia furfur and Malassezia pachydermatis using Agrobacterium tumefaciensmediated transformation. J Microbiol Methods. 2017;134:1-6.

202. Findley K, Oh J, Yang J, Conlan S, Deming C, Meyer JA, Schoenfeld D, Nomicos E, Park M, Program NIHISCCS, et al. Topographic diversity of fungal and bacterial communities in human skin. Nature. 2013:498:367-70

203. Wu G, Zhao H, Li C, Rajapakse MP, Wong WC, Xu J, Saunders CW, Reeder NL, Reilman RA, Scheynius A, et al. Genus-wide comparative genomics of Malassezia delineates its phylogeny, physiology, and niche adaptation on human skin. PLoS Genet. 2015;11:e1005614.

204. Spatafora JW, Chang Y, Benny GL, Lazarus K, Smith ME, Berbee ML, Bonito G, Corradi N, Grigoriev I, Gryganskyi A, et al. A phylum-level phylogenetic classification of zygomycete fungi based on genome-scale data. Mycologia. 2016;108:1028-46.

205. Michielse CB, Salim K, Ragas P, Ram AFJ, Kudla B, Jarry B, Punt PJ, van den Hondel CAMJJ. Development of a system for integrative and stable transformation of the zygomycete Rhizopus oryzae by Agrobacteriummediated DNA transfer. Mol Genet Genomics. 2004;271:499-510.

206. Nyilasi I, Papp T, Csernetics A, Vágvölgyi C. Agrobacterium tumefaciensmediated transformation of the zygomycete fungus Backusella lamprospora. J Basic Microbiol. 2008;48:59-64.

207. Nyilasi I, Ács K, Papp T, Nagy E, Vágvölgyi C. Agrobacterium tumefaciensmediated transformation of Mucor circinelloides. Folia Microbiol. 2005;50:415-20.

208. Papp T, Csernetics A, Nagy G, Bencsik O, Iturriaga EA, Eslava AP, Vágvölgyi C. Canthaxanthin production with modified Mucor circinelloides strains. Appl Microbiol Biotechnol. 2013;97:4937-50.

209. Monfort A, Cordero L, Maicas S, Polaina J. Transformation of Mucor miehei results in plasmid deletion and phenotypic instability. FEMS Microbiol Lett. 2003:224:101-6.

210. Wei D-S, Zhang Y-H, Xing L-J, Li M-C. Agrobacterium rhizogenesmediated transformation of a high oil-producing filamentous fungus Umbelopsis isabellina. J Appl Genet. 2010;51:225-32.

211. Ando A, Sumida Y, Negoro H, Suroto DA, Ogawa J, Sakuradani E, Shimizu S. Establishment of Agrobacterium tumefaciens-mediated transformation of an oleaginous fungus, Mortierella alpina 1S-4, and its application for eicosapentaenoic acid producer breeding. Appl Environ Microbiol. 2009;75:5529-35.

212. Hao G, Chen H, Wang L, Gu Z, Song Y, Zhang H, Chen W, Chen YQ. Role of malic enzyme during fatty acid synthesis in the oleaginous fungus Mortierella alpina. Appl Environ Microbiol. 2014;80:2672-8.

213. Shi H, Chen H, Gu Z, Zhang H, Chen W, Chen YQ. Application of a delta- 6 desaturase with a-linolenic acid preference on eicosapentaenoic acid production in Mortierella alpina. Microb Cell Fact. 2016;15:117.

214. Hao G, Chen H, Gu Z, Zhang H, Chen W, Chen YQ. Metabolic engineering of Mortierella alpina for enhanced arachidonic acid production through the NADPH-supplying strategy. Appl Environ Microbiol. 2016:82:3280-8.

215. Hao G, Chen H, Du K, Huang X, Song Y, Gu Z, Wang L, Zhang H, Chen W, Chen YQ. Increased fatty acid unsaturation and production of arachidonic acid by homologous over-expression of the mitochondrial malic enzyme in Mortierella alpina. Biotechnol Lett. 2014;36:1827-34.

216. Vieira ALG, Camilo CM. Agrobacterium tumefasciens [sic]-mediated transformation of the aquatic fungus Blastocladiella emersonii. Fungal Genet Biol. 2011;48:806-11. 
217. Helber N, Requena N. Expression of the fluorescence markers DsRed and GFP fused to a nuclear localization signal in the arbuscular mycorrhizal fungus Glomus intraradices. New Phytol. 2008;177:537-48.

218. Gietz RD, Schiestl RH. High-efficiency yeast transformation using the LiAc/SS carrier DNA/PEG method. Nat Protoc. 2007;2:31-4.

219. Catlett NL, Lee B-N, Yoder OC, Turgeon BG. Split-marker recombination for efficient targeted deletion of fungal genes. Fungal Genet Newsl. 2003;50:9-11.

220. Cairns TC, Sidhu YS, Chaudhari YK, Talbot NJ, Studholme DJ, Haynes K. Construction and high-throughput phenotypic screening of Zymoseptoria tritici over-expression strains. Fungal Genet Biol. 2015:79:110-7.

221. Kojic M, Holloman WK. Shuttle vectors for genetic manipulations in Ustilago maydis. Can J Microbiol. 2000;46:333-8.

222. Aleksenko A, Clutterbuck AJ. Autonomous plasmid replication in Aspergillus nidulans: AMA1 and MATE elements. Fungal Genet Biol. 1997;21:373-87.

223. Zhu Y, Nam J, Humara JM, Mysore KS, Lee LY, Cao H, Valentine L, Li J, Kaiser AD, Kopecky AL, et al. Identification of Arabidopsis rat mutants. Plant Physiol. 2003;132:494-505.

224. Luo Y, Chen Z, Zhu D, Tu H, Pan SQ. Yeast actin-related protein ARP6 negatively regulates Agrobacterium-mediated transformation of yeast cell. Biomed Res Int. 2015;2015:275092.

225. Ohmine Y, Satoh Y, Kiyokawa K, Yamamoto S, Moriguchi K, Suzuki K. DNA repair genes RAD52 and SRS2, a cell wall synthesis regulator gene $S M I 1$, and the membrane sterol synthesis scaffold gene ERG28 are important in efficient Agrobacterium-mediated yeast transformation with chromosomal T-DNA. BMC Microbiol. 2016;16:58.

226. van Attikum H, Bundock P, Hooykaas PJJ. Non-homologous end-joining proteins are required for Agrobacterium T-DNA integration. EMBO J. 2001;20:6550-8

227. van Attikum $\mathrm{H}$, Hooykaas PJJ. Genetic requirements for the targeted integration of Agrobacterium T-DNA in Saccharomyces cerevisiae. Nucleic Acids Res. 2003:31:826-32.

228. Rolloos M, Dohmen MHC, Hooykaas PJJ, van der Zaal BJ. Involvement of Rad52 in T-DNA circle formation during Agrobacterium tumefaciensmediated transformation of Saccharomyces cerevisiae. Mol Microbiol. 2014;91:1240-51.

229. Soltani J, van Heusden GPH, Hooykaas PJJ. Deletion of host histone acetyltransferases and deacetylases strongly affects Agrobacteriummediated transformation of Saccharomyces cerevisiae. FEMS Microbiol Lett. 2009;298:228-33.

230. Roberts RL, Metz M, Monks DE, Mullaney ML, Hall T, Nester EW. Purine synthesis and increased Agrobacterium tumefaciens transformation of yeast and plants. Proc Natl Acad Sci USA. 2003;100:6634-9.

231. Darwin C. On the origin of species by means of natural selection. London: John Murray; 1859

232. Esher SK, Granek JA, Alspaugh JA. Rapid mapping of insertional mutations to probe cell wall regulation in Cryptococcus neoformans. Fungal Genet Biol. 2015;82:9-21.
233. Shine AM, Shakya VPS, Idnurm A. Phytochelatin synthase is required for tolerating metal toxicity in a basidiomycete yeast and is a conserved factor involved in metal homeostasis in fungi. Fungal Biol Biotechnol. 2015;2:3.

234. McCluskey K, Boundy-Mills K, Dye G, Ehmke E, Gunnell GF, Kiaris H, Polihronakis Richmond M, Yoder AD, Zeigler DR, Zehr S, et al. The challenges faced by living stock collections in the USA. eLife. 2017;6:e24611.

235. Daley M, Knauf VC, Summerfelt KR, Turner JC. Co-transformation with one Agrobacterium tumefaciens strain containing two binary plasmids as a method for producing marker-free transgenic plants. Plant Cell Rep. 1998;17:489-96.

236. Padilla-Guerrero IE,BidochkaMJ.Agrobacterium-mediated co-transformation of multiple genes in Metarhizium robertsii. Mycobiology. 2017:45:84-9.

237. de Boer P, Bronkhof J, Dukik K, Kerkman R, Touw H, van den Berg M, Offringa R. Efficient gene targeting in Penicillium chrysogenum using novel Agrobacterium-mediated transformation approaches. Fungal Genet Biol. 2013;61:9-14.

238. Wang Y, DiGuistini S, Wang T-CT, Bohlmann J, Breuil C. Agrobacterium-meditated gene disruption using split-marker in Grosmannia clavigera, a mountain pine beetle associated pathogen. Curr Genet. 2010;56:297-307.

239. Krenek P, Samajova O, Luptovciak I, Doskocilova A, Komis G, Samaj J. Transient plant transformation mediated by Agrobacterium tumefaciens: principles, methods and applications. Biotechnol Adv. 2015;33:1024-42.

240. Nødvig CS, Nielsen JB, Kogle ME, Mortensen UH. A CRISPR-Cas9 system for genetic engineering of filamentous fungi. PLOS ONE. 2015;10:e0133085.

241. Pohl C, Kiel JAKW, Driessen AJM, Bovenberg RAL, Nygård Y. CRISPR/ Cas9 based genome editing of Penicillium chrysogenum. ACS Synth Biol. 2016;5:754-64.

242. Schuster M, Schweizer G, Reissmann S, Kahmann R. Genome editing in Ustilago maydis using the CRISPR-Cas system. Fungal Genet Biol. 2016:89:3-9.

243. Prieto $M$, Wedin M. Dating the diversification of the major lineages of Ascomycota (Fungi). PLoS ONE. 2013;8:e65576.

244. Giesbert S, Schumacher J, Kupas V, Espino J, Segmüller N, Haeuser-Hahn I, Schreier PH, Tudzynski P. Identification of pathogenesis-associated genes by T-DNA-mediated insertional mutagenesis in Botrytis cinerea: a type 2A phosphoprotein phosphatase and an SPT3 transcription factor have significant impact on virulence. Mol Plant Microbe Interact. 2012;25:481-95

245. Yemelin A, Brauchler A, Jacob S, Laufer J, Heck L, Foster AJ, Antelo L, Andresen $\mathrm{K}$, Thines $\mathrm{E}$. Identification of factors involved in dimorphism and pathogenicity of Zymoseptoria tritici. PLoS ONE. 2017;12:e0183065.

\section{Submit your next manuscript to BioMed Central and we will help you at every step:}

- We accept pre-submission inquiries

- Our selector tool helps you to find the most relevant journal

- We provide round the clock customer support

- Convenient online submission

- Thorough peer review

- Inclusion in PubMed and all major indexing services

- Maximum visibility for your research

Submit your manuscript at www.biomedcentral.com/submit 